\title{
Risk and Return in General: Theory and Evidence
}

\begin{abstract}
Empirically, standard, intuitive measures of risk like volatility and beta do not generate a positive correlation with average returns in most asset classes. It is possible that risk, however defined, is not positively related to return as an equilibrium in asset markets. This paper presents a survey of data across 20 different asset classes, and presents a model highlighting the assumptions consistent with no risk premium. The key is that when agents are concerned about relative wealth, risk taking is then deviating from the consensus or market portfolio. In this environment, all risk becomes like idiosyncratic risk in the standard model, avoidable so unpriced. (JEL D01, D81, G11, G12)
\end{abstract}

\author{
Eric Falkenstein \\ Minneapolis, MN, USA \\ efalken@gmail.com
}

June 2009 
To the degree risk is not diversifiable, someone must hold it, and standard utility theory suggests those who do hold it should be compensated via a risk premium relative to risk-free alternatives. Yet it is striking that a first approximation to risk via volatility or beta against the market return generates no positive risk premiums. Consider that assets such as houses have characteristics that require compensation, such as crime or bad schools, and these factors are abstract in a sense, yet their effects eminently measurable and consistent with intuition (Black 1999; Tita, Petras and Greenbaum 2006). Risk, meanwhile, has devolved into the financial equivalence of dark matter, evident solely by its effects. As asset pricing models have increased in complexity from the simple one-factor CAPM, to "stochastic discount factor(s) ... so general, they place almost no restrictions on financial data" (Campbell (2000)). Explaining asset returns via risk is often more calibration than prediction, as when the risk premiums are functions of atheoretically observed risk factors (see Dai and Singleton 2002; Fama and French 1992).

In my book Finding Alpha, (Falkenstein (2009)), I outline the empirical anomalies to the standard risk-reward theory in asset markets, and provides motivation for my hypothesis that we use relative status, as opposed to absolute wealth, in utility function. The book also addresses the refinements needed to explain why there appears a risk premium in some areas, such as the AAA to BBB bond return spread, or the short end of the yield curve, and argues this is primarily a cash premium, a risk-premium from the super-safe to safe spectrum of risk. Further, there appears a negative risk premium in many highly risky areas, such as for the most volatile stocks. This paper outlines the central theme of that book, documenting the scope of the absence of a risk-return finding, and showing that a relative status utility function is consistent with this as an equilibrium. In section 1, I give an overview of data relevant to the proposition risk is at best uncorrelated with return. In Section 2 I present different models that capture the same idea, 
showing that a relative utility function generates a zero risk premium, and also highlights how heterogeneous agents can generate a negative risk return relation.

\section{The Scope of the Empirical Failure}

As the current extensions to the CAPM via Arbitrage Pricing Theory or Stochastic Discount Factors has no consensus on what that risk factors actually are, this creates a problem in criticizing the general proposition that no risk measure is positively correlated with expected returns. Current asset pricing theory is really a framework, as opposed to a theory, and so any single bit of evidence, such as the low return to highly volatile stocks, in isolation, merely suggest a flawed risk proxy (e.g., volatility). Yet fundamentally, the theory of risk premiums is based on the idea that we do not like things that covary with our wealth, broadly defined, because they increase our net wealth volatility, broadly defined. It seems reasonable to presume, therefore, that priced risk is somehow positively correlated with volatility, because volatility is positively correlated with CAPM betas. Intuitively, the ultimate priced risk factor(s) should also be correlated with betas and volatility.

Thus, the most damning evidence is the scope of the volatility-return correlation failure across many asset classes. This evidence has never been presented as an argument for the failure of the conventional theory because as this theory cuts across several asset classes, each with their own measurement and stochastic characteristics, a single statistical test is difficult if not impossible. But the welter of data is broad, and examples of a volatility-return relation are the anomalies, rather than the observation that risky securities have lower returns in a particular asset class. 
A. Total Volatility and Cross-Sectional Returns

My dissertation was titled 'Mutual Funds, Idiosyncratic Variance, and Asset Returns.' Its central focus was the negative relation between idiosyncratic risk is negatively related to returns (Falkenstein (1994)). Ang, Hodrick, Xing and Zhang (2006) documented the relationship between idiosyncratic variance and returns, cross sectionally, and followed this up with another paper documenting it internationally (Ang, Hodrick, Xing, and Zhang (2009)).

Figure 1 shows the average excess returns for quintiles sorted by idiosyncratic volatility. Excess returns', which are like the alpha in a market model that includes factors, in this case, the 4-factor Fama-French factors. You take the total returns, and subtract the 'factor returns', because the excess return is that which is unexplained by the Fama-French factors. As these factors are generally positively correlated to variance, that merely increases the alpha, because total volatility and beta are positively correlated, meaning highly volatile stocks have a higher beta and higher expected return. The excess returns show a strong negative relation to idiosyncratic volatility. The following year, they documented this effect in 23 developed country markets and leave this finding as a global puzzle. 


\section{Figure 1.}

\section{Annual Excess Returns to G-7 Equities Sorted by Idiosyncratic Volatility}

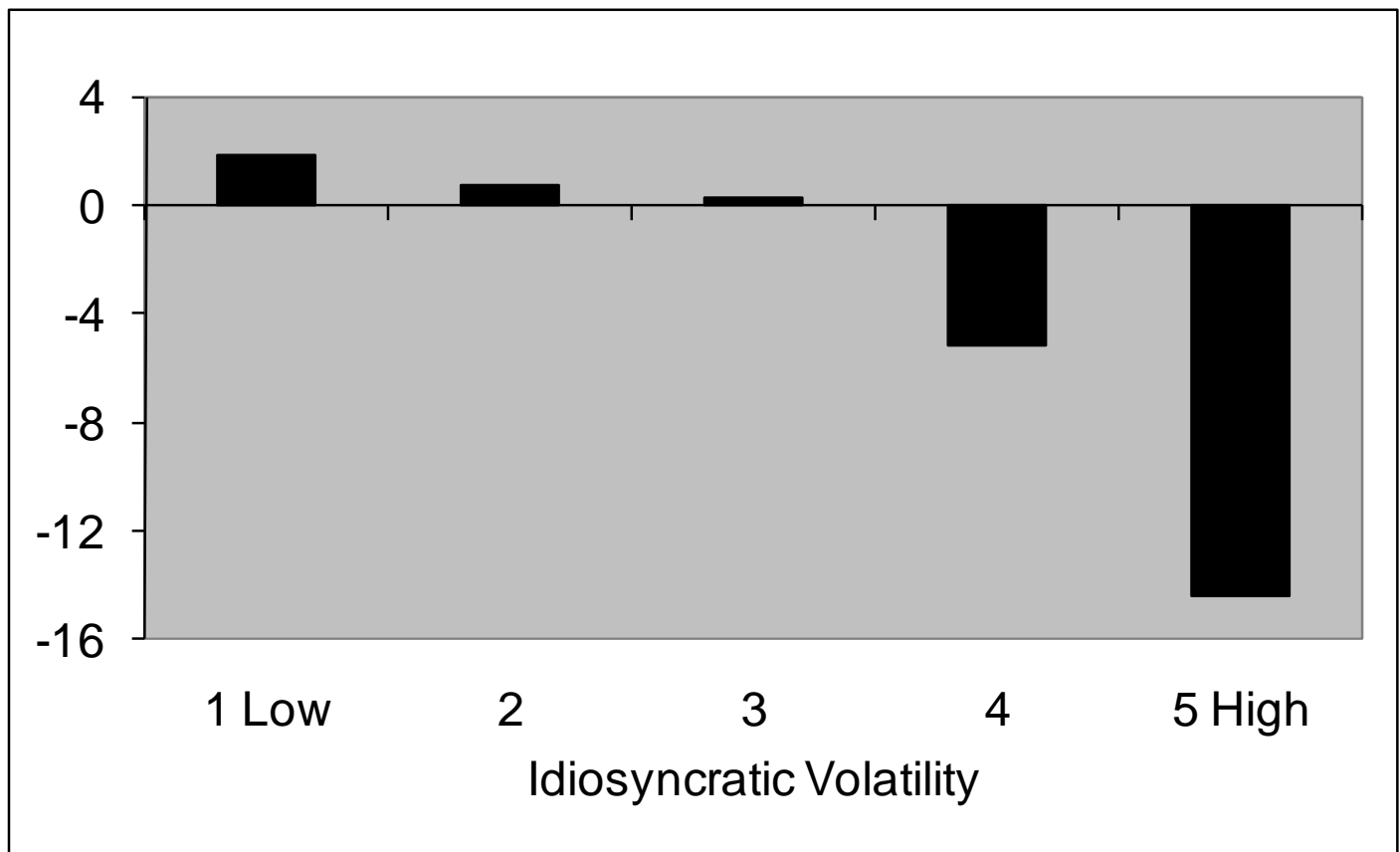

From Ang, Hodrick, Xing and Zhang 2007, Table 7. Returns are annualized. 1963-03

\section{B. Beta and Returns}

It is well known that a CAPM beta, in the context of size, is unrelated to returns (Fama and French (1992)). Yet the connection between beta and returns is actually much worse than that when put into tangible investable portfolios. Table I shows the returns to various portfolios grouped by their betas. This used an investable universe, which was assumed to have a lower bound at the twentieth percentile of the NYSE listed firms at any time. As Nasdaq and AMEX firms are generally smaller, this gets rid of about half of the stocks actually listed currently, but it is more realistic in that it corresponds currently to about a $\$ 500 \mathrm{MM}$ market capitalization cutoff. Most institutional investors are wary of going much below this because it gets difficult to 
put on large positions, and using the percentile we can account for the upward drift in the average market capitalization of this period. As the equity market has become broader over time, going back to 1962 this rule only exclude the bottom $20 \%$ of stocks with at least 36 monthly returns, while currently it excludes about $50 \%$ of all companies. No ETFs, REITs, closed-end funds, etc. All common stocks. Data were taken from 1962 through March 2009. Only monthly data were used prior to 2000 , but subsequent to that this was combined with daily return data, so that the beta estimates are better in the more recent period (prior 36-60 months for the monthly data, prior year for daily data).

\section{Table I}

\section{Statistics to Portfolios Sorted by Betas, 2/1962-3/2009}

Betas are constructed from monthly data, the prior 36-60 months as available. Beta-Low and Beta-High are the extremum 100 low and high beta stocks. Beta 0.5, 1.0, and 1.5 are from the 100 stocks nearest these numbers. Portfolios are formed every 6 months. Daily data is used for betas after 2000 .

\begin{tabular}{|c|c|c|c|c|c|c|c|}
\hline & Beta- & & & & Beta- & & Equal \\
& Low & Beta-0.5 & Beta-1.0 & Beta-1.5 & High & S\&P500 & Weighted \\
\hline AnnRet Arith & $11.20 \%$ & $11.50 \%$ & $12.60 \%$ & $11.80 \%$ & $10.90 \%$ & $10.30 \%$ & $12.11 \%$ \\
\hline AnnRet Geo & $10.90 \%$ & $11.40 \%$ & $11.60 \%$ & $8.70 \%$ & $5.20 \%$ & $9.50 \%$ & $10.99 \%$ \\
\hline AnnStdev & $13.10 \%$ & $11.60 \%$ & $17.40 \%$ & $26.20 \%$ & $33.90 \%$ & $15.00 \%$ & $17.74 \%$ \\
\hline Beta & 0.58 & 0.57 & 1.04 & 1.44 & 1.78 & 1.00 & 1.03 \\
\hline Sharpe & 0.41 & 0.51 & 0.36 & 0.12 & -0.01 & 0.27 & 0.31 \\
\hline
\end{tabular}


We see that average arithmetic annual returns are highest for the Beta-1.0 portfolio. This portfolio contains only those stocks were the prospective beta forecast is closest to a beta of 1.0 , thus trimming off the higher and lower beta equities. The beta 0.5 , and beta 1.5 , similarly targeted those numbers. Over this period, we see the average beta actually experience by these portfolios was closer to one, reflecting some of the ineradicable mean reversion in beta. Nonetheless, they were relatively close to their beta targets. The high and low beta portfolios, meanwhile, were merely the 100 most extreme projected betas, and these betas varied considerably over the 47 year period.

The interesting thing is that returns are not increasing in terms of beta, and this suggests several obvious investing strategies for those who do care about beta. This becomes even clearer when one uses geometric returns as opposed to arithmetic returns, because arithmetic returns are for someone investing a fixed amount, each month, whereas the geometric return is for the buyand-hold investor, the latter being more relevant to the longer term investor. These geometric returns really fall off for the higher beta portfolios.

Because this sample selected from about 2000 stocks currently, it tended to have a more equal-weighted bias than the S\&P500, which is value weighted. The "equal weighted" column on the far right of Table I shows the equal weighting of stocks within the 20th percentile of NYSE market cap cut-off. As smaller stocks strongly outperformed larger stocks in this period, the average return among these equities is higher than for the S\&P500 by about 150 basis points annually. Yet the Beta 1.0 portfolio generates a good 61 basis point lift relative to this effect, highlighting that the Beta 1.0 portfolio, by excluding the low-returning, high beta stocks, dominates the index with the same beta.

D. Call Options. 
Theoretically, beta—or any covariance with the elusive risk factor—measures the 'how much' of risk, and so if risk is priced, options with higher strike prices (ie, more out-of-themoney), have higher beta(s) per dollar invested, which implies higher average return. Therefore far out-of-the-money call options should offer extremely high expected returns as a percent of their price. As underlying stocks always, in practice, have positive CAPM betas, all calls will have positive betas that exceed the beta of the underlying stock, and call betas will increase in the strike price as the calls get further out-of-the-money. Hence, all calls will have positive expected returns and the expected returns will be larger for greater strike prices, because the betas, as a function of the call price, increase as you go out of the money. Coval and Shumway (2001) prove that expected European call returns must be positive and increasing in the strike price provided only that (1) investor utility functions are increasing and concave and (2) stock returns are positively correlated with aggregate wealth. 


\section{Figure 2.}

Monthly Reruns for Call Options Ranked by their Sensitivity to Stock Price

(Omega)

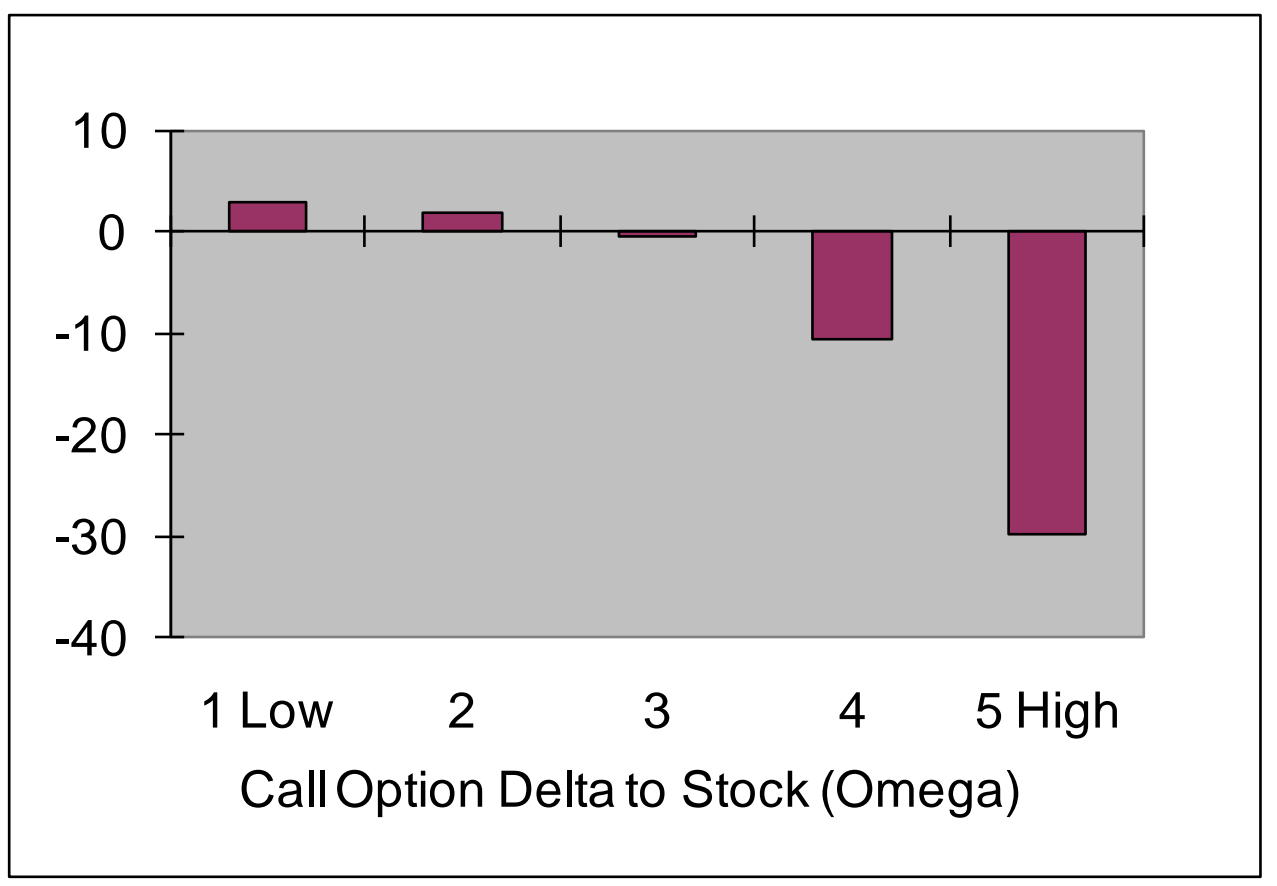

Sophie Ni (2007). Table 5

Sophie Ni (2007) looked at data from 1996 through 2005, and found that the highest outof-the-money calls, with one month to expiration, have average returns of $-37 \%$, over a month! Figure 2 above shows that if you bucket call options into groups based on their 'deltas', you find that call options, indeed, are indeed highly levered stock positions. Lower deltas mean the call option is less sensitive, in dollar terms, to a stock moving, but more sensitive, in percentage terms. Thus, an at-the-money call option with a delta of 0.5 move 0.5 dollars for every 1 dollar move in the underlying, while an out-of-the-money option may have a delta of 0.08 . On a percentage basis, since the at the money option has a price of around 5, while the out-of-the- 
money option a price of 0.25 , the percent change in price for the low delta option is much greater. The key to remember is that the average stock has a beta of 1.0 , these betas range from 4 to 15 - giving one 4 to 15 times the juice of the daily return. An option's beta is the beta of the stock, times the 'omega', which is a measure of the percent return in the option price given a $1 \%$ change in the stock price. If the omega on a Ford call option is calculated to be 1.6, then for every $1 \%$ change in the price of Ford the price of the call option will rise by $1.6 \%$.

Not only is the average return negative for call options, these returns get worse the more implicitly levered, the more 'risky', the options become, in contrast to what the weak assumption described by Coval and Shumway. Returns are negatively correlated with the betas. Investors basically are overpaying for lottery tickets when they buy options, and just like the lottery, the average payout is worse they more risk one takes. If there's a risk premium in equities, it certainly is not amplified in options in any way, because you lose money, on average, buying leverage market positions via call options

\section{E. Private Investments}

Entrepreneurial investment, such as in small proprietorships (S-corps and private LLCs) is a highly undiversified investment for most entrepreneurs. The reasons are straightforward, in that when one person has a significant effect on the business through his effort and competence, it is natural that he should have the most 'skin in the game'. This is a classic issue of moral hazard because a business manager, who has significant upside and, without ownership, no downside, is motivated to take wild risks on the theory of heads I win, tails the banker loses. However, if the manager is the majority owner, his failure should affect his net wealth too. About 75 percent of all private equity is owned by households for whom it constitutes at least half of their total net worth. Furthermore, households with entrepreneurial equity invest on 
average more than 70 percent of their private holdings in a single private company in which they have an active management interest. Despite this dramatic lack of diversification, private equity returns are on average no higher than the market return on all publicly traded equity. Figure 3 shows the basic results of Moskowitz and Vissing-Jorgensen (2002), that over an 8 year period, if anything returns to private business, be it partnerships, proprietorships, $\mathrm{S}$ corps, $\mathrm{C}$ corps, and two entirely different sets of data, there is no demonstrable premium. Given an investor can invest in a diversified, and liquid equity portfolio, it is puzzling why households willingly invest substantial amounts in an asset with an equivalent return, but much higher volatility, including a positive correlation with the market.

\section{Figure 3.}

\section{Annual Returns to Small Business Investments}

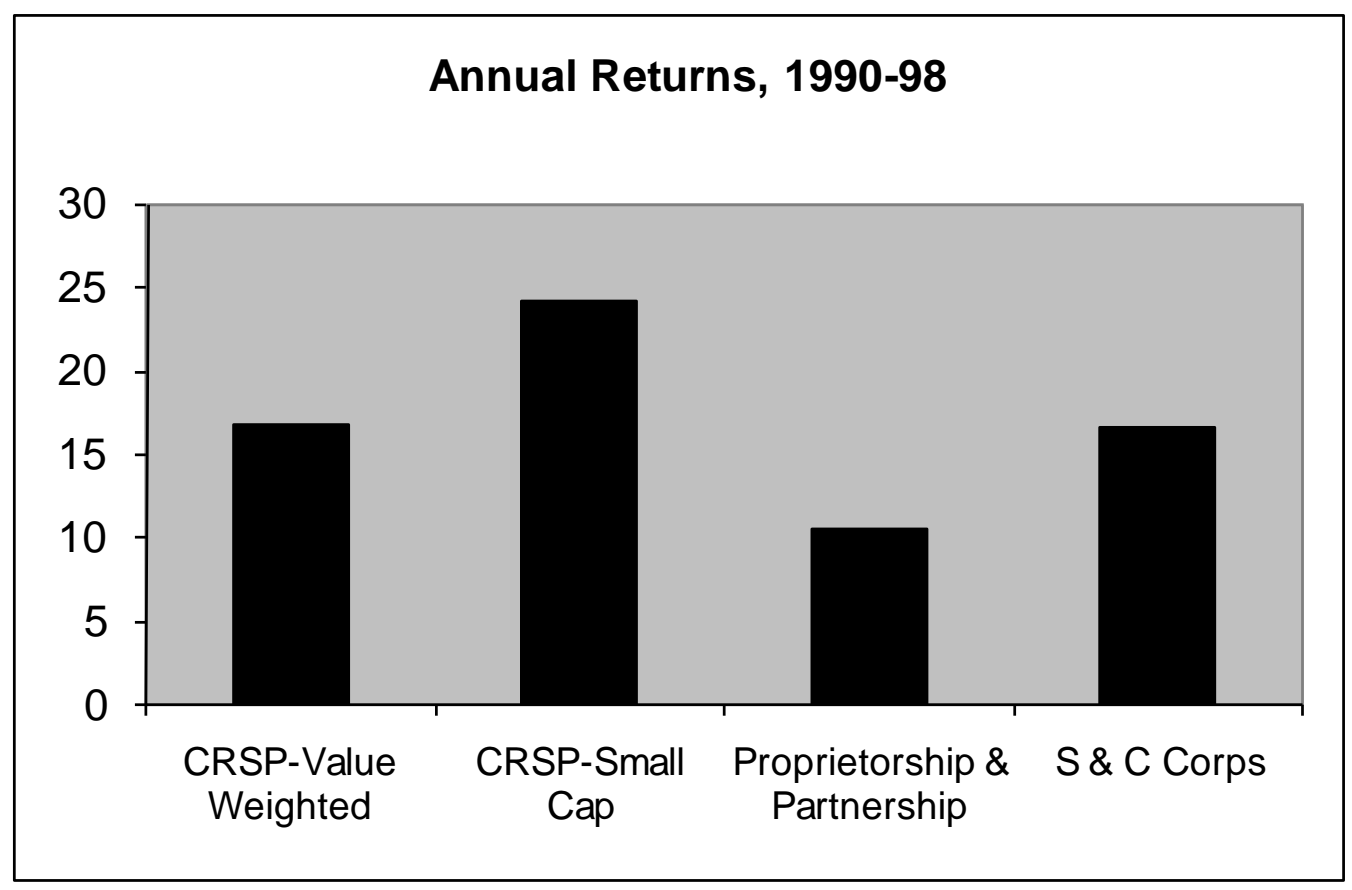

From Table 4, Moskowitz, Tobias J, and Annette Vissing-Jorgensen. 2002. "The Returns to Entrepreneurial Investment: A Private Equity Premium Puzzle?,"92(4), pp. 745-78 
The forced nondiversification of a private equity investment, from a pure portfolio perspective, implies a requisite higher return. Using standard utility models to calibrate the hurdle rate that would make a household indifferent between investing in a portfolio of a single private firm, a public equity index, and T-bills, or a portfolio of just the public equity index and T-bills, researchers estimate that private equity risk generates a hurdle rate of about 10 percent higher the public equity return (Heaton and Lucas (2000)). You should receive a huge premium for the large idiosyncratic risk you are taking, risk that unlike idiosyncratic risk in the market, is impossible to diversify away. Entreprenuers appear to be taking extra risk, for no extra return.

\section{F. Leverage and Returns.}

The Miller-Modigliani theorem states that regardless of the debt and equity proportions, the value of the firm is the same. As a firm increases its leverage using more debt, its equity concentrates the variable returns of the business on a smaller and smaller base, making them both riskier: the equity's beta and volatility will increase, the debt will have a higher chance of defaulting. The implication is that highly levered firms should have lower rated debt (junk), and more volatile equity, but because debt has a lower return than equity, the net, total return to all a company's securities (debt and equity) is a constant. 


\section{Figure 4.}

\section{Annual Return to Portfolios sorted by Market Leverage (Debt/Market Cap)}

Adjusted for Book/Market and Size Exposure

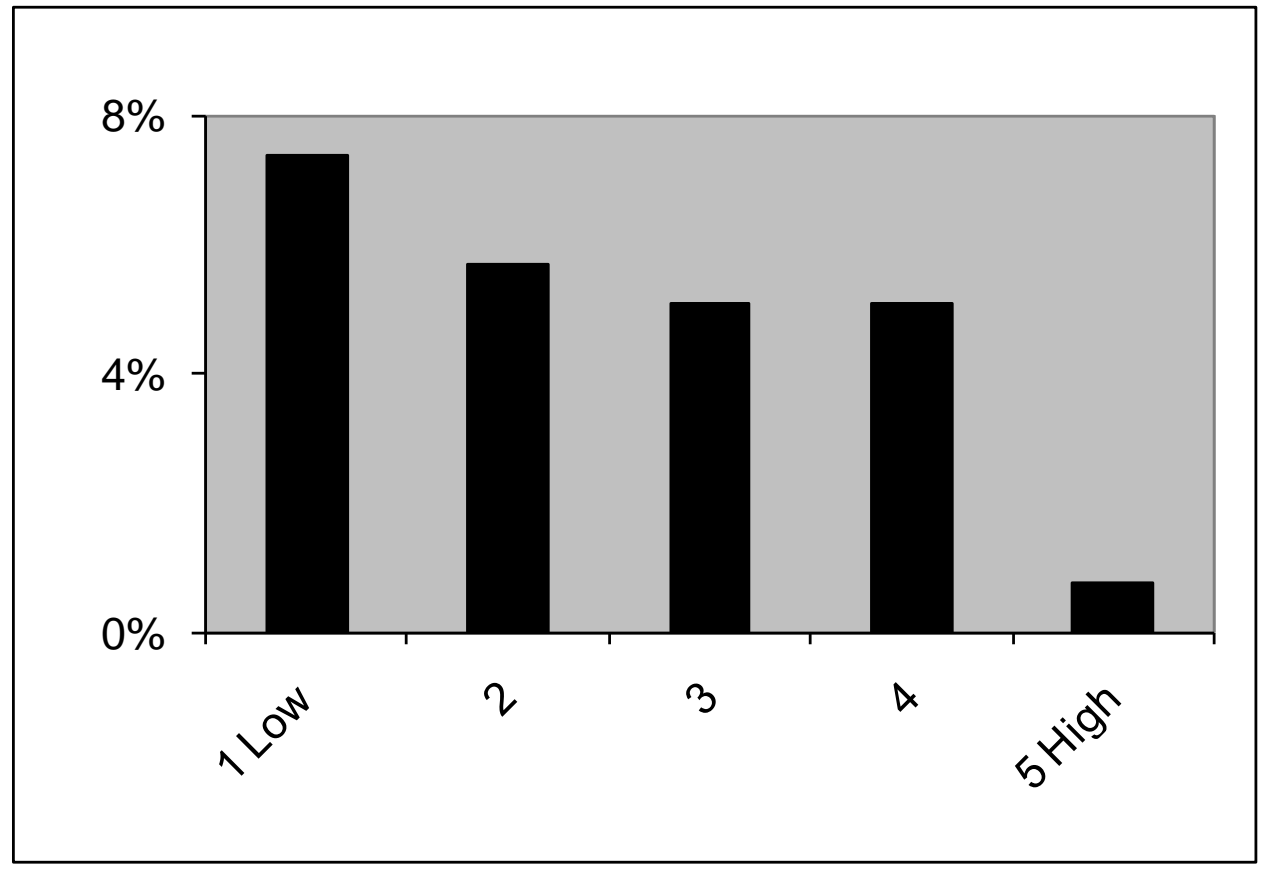

Penman, Richardson, and Tuna, 2007, Table 1

In figure 4 above, we see that leverage is, anomalously, clearly negatively correlated with returns. These researchers held constant size and book/market. Higher leverage implies lower returns for equity even though this should increase risk of that equity, and thus should increase returns (Haugen and Baker (1996), Penman, Richardson, and Tuna (2007)) . Further, there have been no papers linking how leverage is positively related to expected returns, even though this result would have been consistent with a Nobel-prize winning theory. Empirically supporting Nobel-winning theory for the first time is worthy of a publication in a top journal, and for 
academics, this is their number one priority. The absence of a positive finding in this context is perhaps more powerful than the handful of negative results.

\section{G. Mutual Funds}

The original tests of the CAPM were on mutual fund returns, hoping to show that mutual fund performance would be explained by the new risk factor (Sharpe (1965), Treynor and Mazuy (1966). Subsequent work found no relationship between a stock's return and its beta, and it was sufficiently uninteresting that in more recent work, the relation between beta and returns is addressed only as an aside in Malkiel (1995), who notes that a fund manager's beta is uncorrelated with his fund's average return.

As with leverage studies, the absence of any volatility or beta correlation with mutual fund returns is most relevant here, because it highlights an absence of confirmation in an area examined since the very beginnings of asset pricing theory. Absense of evidence is evidence of absence from a Bayesian perspective, not proof, but suggestive especially when you know there has been a systematic, thoughtful search for such evidence. Carhart (1997) presented a well documented study of mutual funds is most well known for introducing 'momentum' as a factor, akin to Fama and French's value and size factors, but it was also notable for the manifest irrelevance of 'beta' in his analysis. Good or bad, a mutual fund's beta was never an issue in explaining the results, and so that paper hardly mentioned the null results, and instead centered on the importance of momentum as a 'factor' that explained the positive one-year persistence. Later studies of mutual funds by Wermers (2000) does not even address beta.

\section{H. Currencies}


Uncovered Interest Rate Parity is a theory that connects current to future spot rates. This theory states that you have two ways of investing, which should be equal. First, you can invest in your home country at the riskless rate. So if the US interest rate is $5 \%$, you can make a $5 \%$ return in one year, in USD. Alternatively, you can buy, say, yen, invest at the yen interest rate (each currency has a different risk-free rate), and then convert back to USD when your riskless security matures. For this to be equal, you need something like

$$
r_{U S D}=r_{y e n}+\% \text { change in yen }
$$

Where $r_{\text {usd }}$ is the US interest rate, etc. So, if you make 5\% in USD, an American investor should receive that same return in yen, via the interest rate in yen, plus the expected appreciation/depreciation in the yen against the dollor. If the interest rate in yen is $1 \%$, this means one expects the yen to appreciate by $4 \%$ against the dollar. When the foreign interest rate is higher than the US interest rate, risk-neutral investors should expect the foreign currency to depreciate against the dollar by the difference between the two interest rates. This way, investors are indifferent between borrowing at home and lending abroad, or the converse. This is known as the uncovered interest rate parity condition, and it is violated in the data except in the case of very high inflation currencies. In practice higher foreign interest rates predict that foreign currencies appreciate against the dollar, making investing in higher interest rate countries winwin: you get appreciation on your currency, and higher riskless interest rates while in that currency.

Now the rates of expected return via the two investment paths can differ according to risk, of course. So one can imagine, looking at the yen, or the dollar, or various European currencies in the 1970's, etc., trying to tie each to some measure of a home currency's risk factor: consumption, the stock market. 
Like high returns to low volatility stocks, it is difficult, but not theoretically impossible, to make sense of this. Hodrick (1987) wrote a comprehensive technical overview of the theory and evidence of currency markets in 1987. Hodrick looked at CAPM models, latent variable models, conditional variance models, models that use expenditures on durables, or nondurables and services, Kalman filters. None outperformed the spot rate as a predictor of future currency prices. Hodrick leaves off with the idea that 'simple models may not work well'. He summed up his findings in this paragraph:

"We have found a rich set of empirical results... We do not yet have a model of expected returns that fits the data. International finance is no worse off in this respect than more traditional areas of finance."

For the next 20 years, and many hedge funds specialized in the 'carry trade', which was as simple as it was successful: lend capital to high interest rate currencies, enjoy the high riskless rates and currency appreciation on the spot rate; borrow capital at the low interest rate currency, and make money on the depreciation of this debt over time. In 2008 these strategies suffered significantly, but the net effect is still there is no clear relation between risk and return in currencies.

Brunnermeier, Nagel and Pedersen (2008) noted that

Overall, we argue that our findings call for new theoretical macroeconomic models in which risk premia are affected by funding and liquidity constraints, not just shocks to productivity, output, or the utility function.

By 'our findings' they mean, the carry trade continued to work 30 years after being identified by Farber and Fama (1979), and it has continued as a puzzle because no reasonable risk factor can explain it. 


\section{World Country Returns}

Erb, Harvey and Viskanta (1995) look at data from 1979-92 between developed and nondeveloped countries. As the arithmetic returns are much higher than the geometric returns, he highlights those monthly returns for displaying a risk premium based on the volatility, but if you look at the geometric returns, they are about the same as the developed country data (13.5\% for developing, 12.3\% for developed). Using a broader set of data from 1989 through 2000, Bansal and Dahlquist (2002) report approximately similar arithmetic returns (15.8\% vs. 16.1\%), but then using annualized geometric returns, the return for the developed countries was $13.8 \%$ vs. $6.7 \%$ for the developing countries.

Thus it is interesting that among country equity returns, there is no clear risk premium. Dimson, March, and Staunton (2006) find that the USA had about the same average return relative to short term debt from 1900-2005 compared to 17 other developed countries worldwide, about 5\%. Figure 5 shows the volatility and returns for 17 countries over the 1900-2005 period.

\section{Figure 5}

Equity Premiums vs. Volatility for 17 Country Returns, 1900-2005

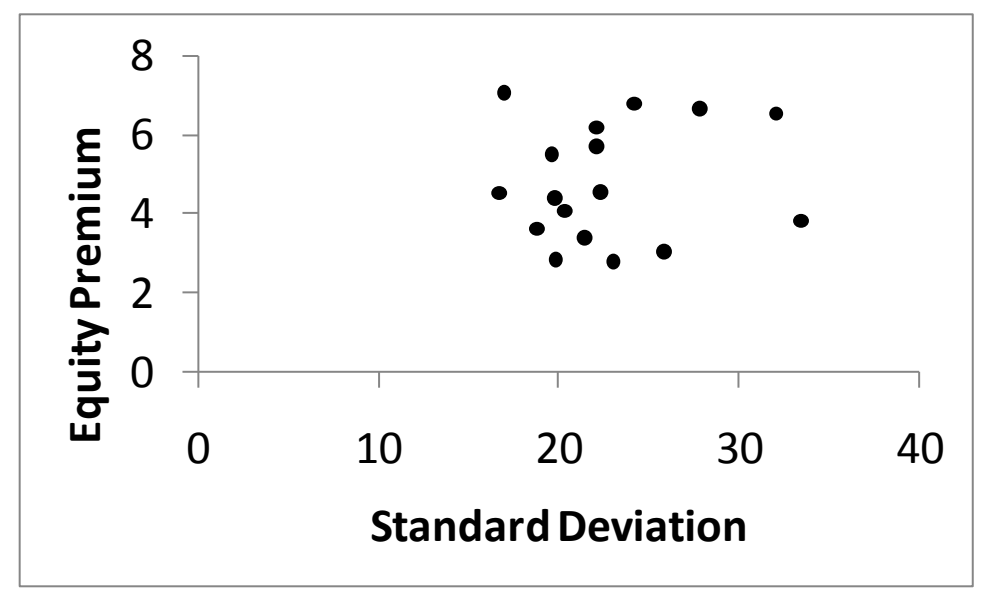

From Dimson, Marsh, and Staunton (2006). 
It is strange that there is not a pattern among their returns in terms of volatility, because intuitively, those countries where the stock market index is especially volatile, would have a higher risk premium, as foreigners would not be able to invest sufficiently due to tax and institutional reasons, and eliminate the risk premium for this idiosyncratic risk. One can look for global risk factors that explain this, and the usual ones (eg, a world stock market index) do not work.

\section{J. Corporate Bonds}

The conventional corporate bond puzzle is that spreads are too high. The most conspicuous bond index captures US Baa and Aaa bond yields going back to 1919, which generates enough data to make it 'the' corporate spread measure, especially when looking at correlations with business cycles. Yet Baa bonds are still 'investment grade', and have only a 4.7\% 10 year cumulative default rate after initial rating. As the recovery rate on defaulted bonds is around $50 \%$, this annualizes to a mere $0.23 \%$ annualized loss rate. Since the spread between Baa and Aaa bonds has averaged around 1.2\% since 1919, this generates an approximate $0.97 \%$ annualized excess return compared to the riskless Aaa yield, creating the puzzle that spreads are 'too high' for the risk incurred.

Altman and Bana (2004) and Kozhemiekin (2007) note there is no premium to 'High Yield' portfolios relative to investment grade portfolios, a set of bonds with a 3.84\% average annual default rate from 1970-2005. Further, Altman and Stoneberg (2006) note that a bankrupt bond portfolio underperforms investment grade bonds. Both High Yield and Bankrupt bonds have more volatility and cyclicality than investment grade bonds, and do their worst when returns are most valued, in bad times. Junk bonds are intuitively risky. Data from the Merrill 
Lynch High Yield index show an 6.77\% annualized return relative to the $7.18 \%$ return of their investment grade index from 1987 through December 2008.

Indices are really an overstatement because how such indices have a systematic bias when portraying illiquid or unaudited asset classes. For a long time, average junk bond's bid-ask spreads were 10 points wide, and this transaction cost is implicit in the fact that for a set of mutual High Yield mutual funds that currently exist (ie, obvious survivorship bias), their total annualized return from 1987-2008, was 3.44\%, whereas the Merrill High Yield Index rose 6.77\% (see figure 6 below). Investment Grade funds underperformed their index by much less, in that the Index return was $7.18 \%$ compared to fund returns of $6.48 \%$. The simple idea is that illiquid assets have higher transaction costs, higher ' management fees', that cause actual performance to be lower than that of an index. Thus the closing prices of illiquid assets, such as in an index, will be a biased proxy for real returns if based on merely closing prices. If you take a couple percent off the high yield index due to price impact, commissions, bid-ask spread, there is a negative risk premium to these risky assets. 


\section{Figure 6}

\section{Total Returns to Corporate Bonds, 1987-2008.}

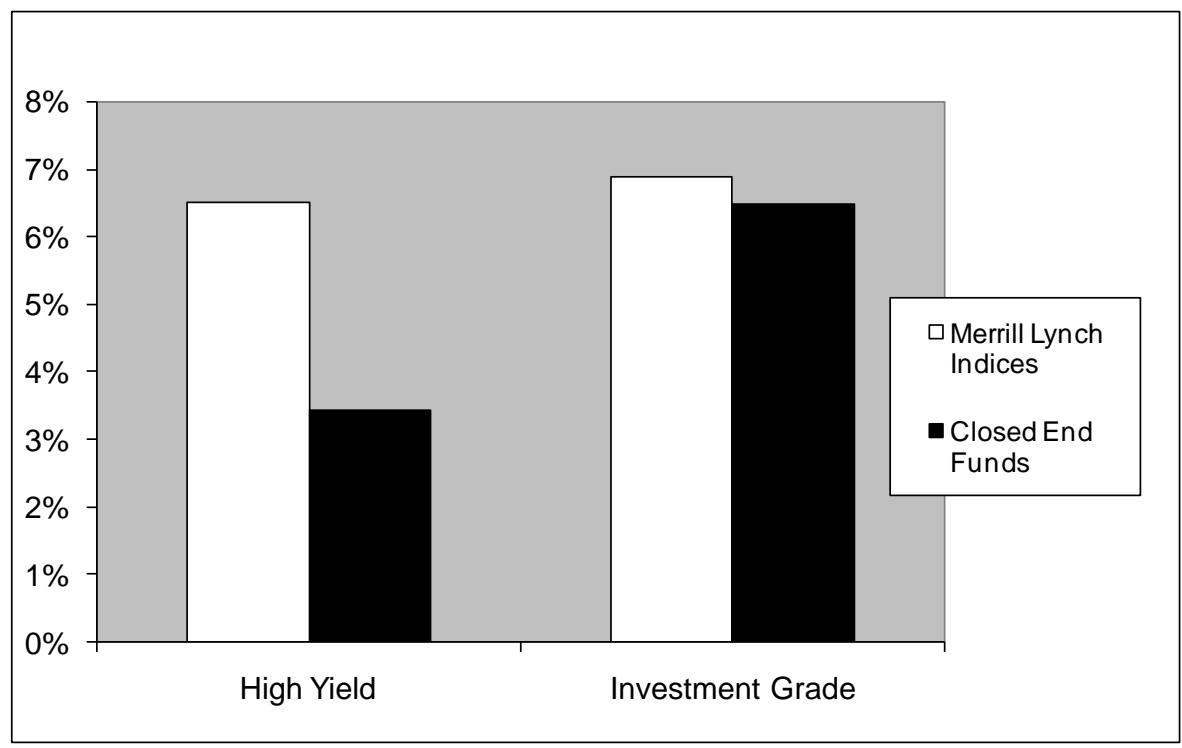

Data are from the Merrill High Yield Master II and Merrill BBB-AA Index (H0A0 and C0C0, respectively). Closed end fund data are from Bloomberg.

Therefore, the excess corporate risk premium puzzle pertains to one portion of the risk spectrum the difference between a $0.03 \%$ (AAA) and a $0.3 \%$ (BBB) annualized default rate, a distinction without a difference to many investors. When one goes from a $0.3 \%$ to a $15 \%$ default rate, as one does when you go from BBB to $\mathrm{C}$ rated bonds, there is no return premium at all. Given reasonable expectations of transaction costs, and the actual difference between the high yield indices and actual high yield returns, it seem probable people extend into higher credit risk with a lower average return. It is difficult to see how the little risk is priced, the big one not, if risk is to have any consistent meaning. If the 'corporate spread' is a function of risk at one end, why is it not at the other, more intuitive end?

\section{K. Yield Curve}


he general shape of the yield curve is as follows. It rises until about 3 years, then flattens out. While this may be deceiving because bond prices have positive convexity, in practice this effect on US Treasury returns, and yields, is basically the same in the post 1954 period.

Thus, I took data on US government bond yield since 1958 through 2008 from the Fed's H.15 report, and constructed a set of annualized returns based on a buy-and-hold strategy. Each monthly return subtracted the Fed Funds rate, and included both the monthly price appreciation plus the coupon yield. These data are presented in figure 6 below.

\section{Figure 6}

Total Return and Standard Deviation to Long Treasury Bond Positions, 1958-2008

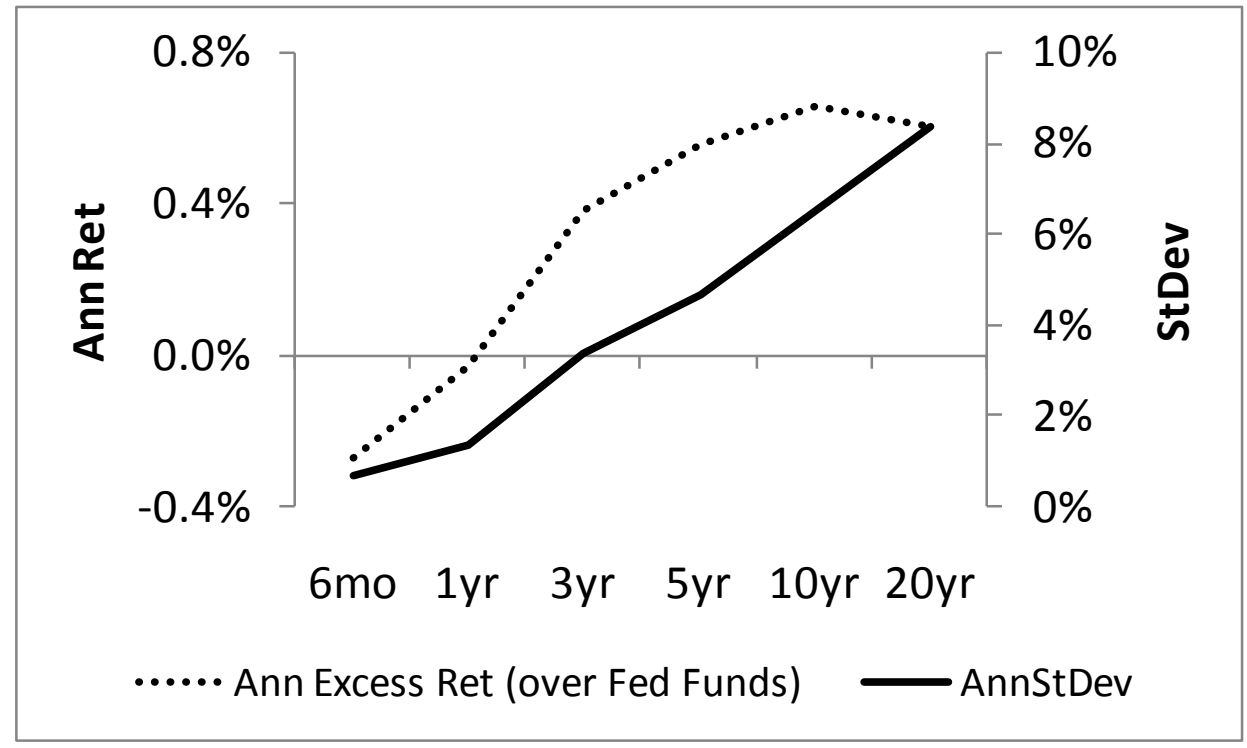

As we can see, the returns to a funded position in bonds, an excess return, is very close to zero over this period. Indeed, buying 6-month T-bills funded at the Fed Funds rate was a money loser, and for the 1-year bond, about a zero return. Returns are increasing over maturity, yet, the 
increase in yield from 5 years to 10 years is miniscule, from $0.55 \%$ to $0.65 \%$, and it actually decline to $0.60 \%$ for the 20 year bonds. 30 year bond data starts in 1977 , and has a 2 year gap around 2003, and the data ovelapping with the 20 year suggest a slightly (10 basis point) lower annualized return from 20 to 30 years. It is fair to say the returns to yield curve extensions past five years are basically zero. The price volatility, meanwhile, increases consistently as maturity increases, and thus the Sharpe ratio, the ratio of the return on the bond minus a risk free rate, falls as the maturity increases beyond 5 years. The risk premium from 3-months to 3-5 years does not extrapolate.

\section{Futures}

Futures are derivative securities, bilateral agreements, one side to buy, the other to sell, at a future date, a spot commodity at a prespecified price. Futures returns are not driven by lower expected spot prices because such prices are reflected in a low current futures price (Black, (1976)).

What return can an investor in futures expect to earn if he does not benefit from expected spot price movements, and is unable to outsmart the market? The difference between the current futures price and the expected future spot price. Assume the current futures price is below the current spot price. Usually, this implies the expected spot price is above the futures price (we don't truly observe the actual expected futures price, but this is generally true). On average, going long the futures makes money when it is below the current spot price because the futures price rises to the eventual spot price. At maturity, while the spot price may have fallen, the futures price has risen too. This is called 'normal backwardization' because if you put the futures prices out like a bond yield curve (yields up, prices down), the more distant futures prices are below the current price. 


\section{Figure 7}

Forward Curves in August 2008. Gold in Contango, Copper in Normal Backwardization.

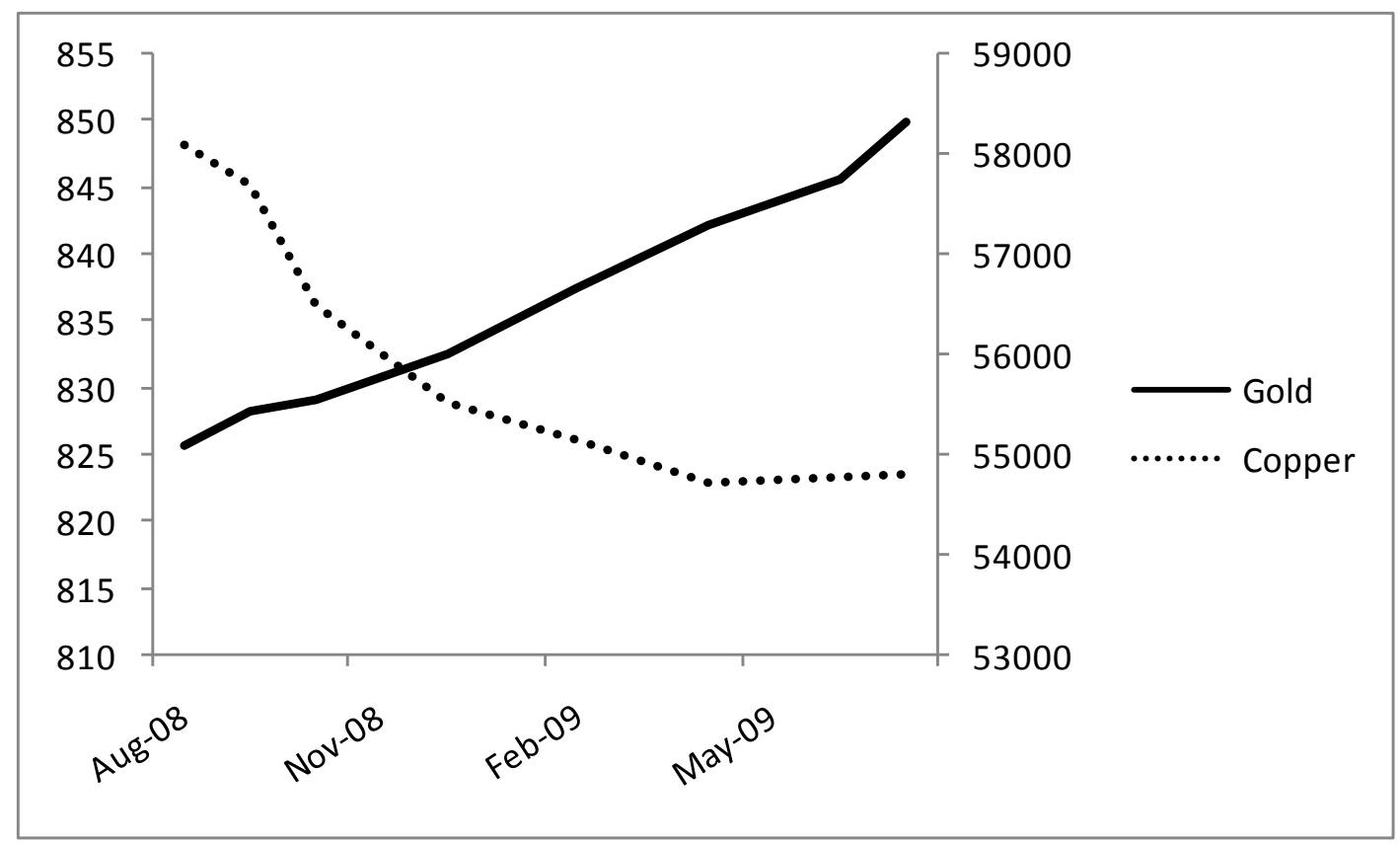

Figure 7 shows the term structure of futures for Gold and Copper in August 2008.

Copper is in backwardization, while Gold is in 'contango', a fun name for the opposite.

Historically, gold is always in contango, meaning, if you are long gold futures, you lose money on average as it rolls to maturity. Other commodities flop around, sometimes flat, sometimes in normal backwardization, and sometimes in contango. Harvey and Erb (2006) find that copper, heating oil, and live cattle were on average in backwardization, while corn, wheat, silver, gold and coffee were in contango, on average.

The expected roll returns (called because the futures prices 'rolls' to the current spot price over time), based on the current relation of the futures to the spot, are uncorrelated with the prominent risk factors for equities (ie, the market, value, and size factors) or for corporate bonds 
(ie, the Baa-Aaa yield spread). Changes in inflation adversely affects the roll returns from normal backwardization, while adversely affecting the roll returns for contango (see Gorton, and Rouwenhorst (2005)).

There are predictable returns in futures returns, primarily due to the roll, which is foreseen in the current relation of the futures price to the spot price. But what drives this, from a risk perspective, is a mystery.

\section{Distress Risk}

Early on in the size effect, researchers were at a loss to figure out what kind of risk that firm 'size', outside of beta, captured. The obvious risk, residual risk from these very small stocks, was diversifiable, and so not risk. Fama and French suggested that both the value premium and the small stock premium were related to some sort of distress factor, that is, value stocks, whose price was beaten down by pessimists, and small stocks, which had less access to capital markets, probably had more risk of defaulting, if the economy faltered. It may not show up in correlations or covariances, but that's merely because such risks are very episodic like the risk of a heart attack: The first symptom of a heart attack is a heart attack.

Dichev (1998) had documented this, but this finding could be dismissed because he presumably had a poor default model (he used the Altman's (1968) model that was based on only 33 defaulting companies). Then several others documented a similar result, and finally Campbell, Hilscher, and Szilagyi (2005) find the distress factor can hardly explain the size and book or market factors; in fact, it merely creates another anomaly because the returns are significantly in the wrong direction. Distressed firms have much higher volatility, market betas, and loadings on value and small cap risk factors than stocks with a low risk of failure; furthermore, they have much worse performance in recessions. These patterns hold in all size 
quintiles but are particularly strong in smaller stocks. Distress was not a risk factor that generated a return premium, as suggested by theory, but rather a symptom of a high default rate, high bond and equity volatility, high bond and equity beta, and low equity return.

While I was at Moody's in 2000, I was able to use their database of ratings back to 1975 and find that the rate of return lined up almost perfectly with the rating, with AAA having the highest return, C the lowest. Updating that data using S\&P ratings, and used the rating in June, to form a portfolio over the following 12 months, a very straightforward strategy. I use 1987 as the starting point here because prior to this junk bonds, those with rating below investment grade, were small in number, as there was a structural shift in the junk market in the late 1980's when these instruments started to have good pricing data (this does not change the results anyway). 


\section{Figure 8}

\section{Annual Stock Returns to Portfolios Formed by Rating}

\section{$1988-2008$}

Portfolios were formed every June. Firms delisting within the 12 months were then reallocated to the remainder of the portfolio

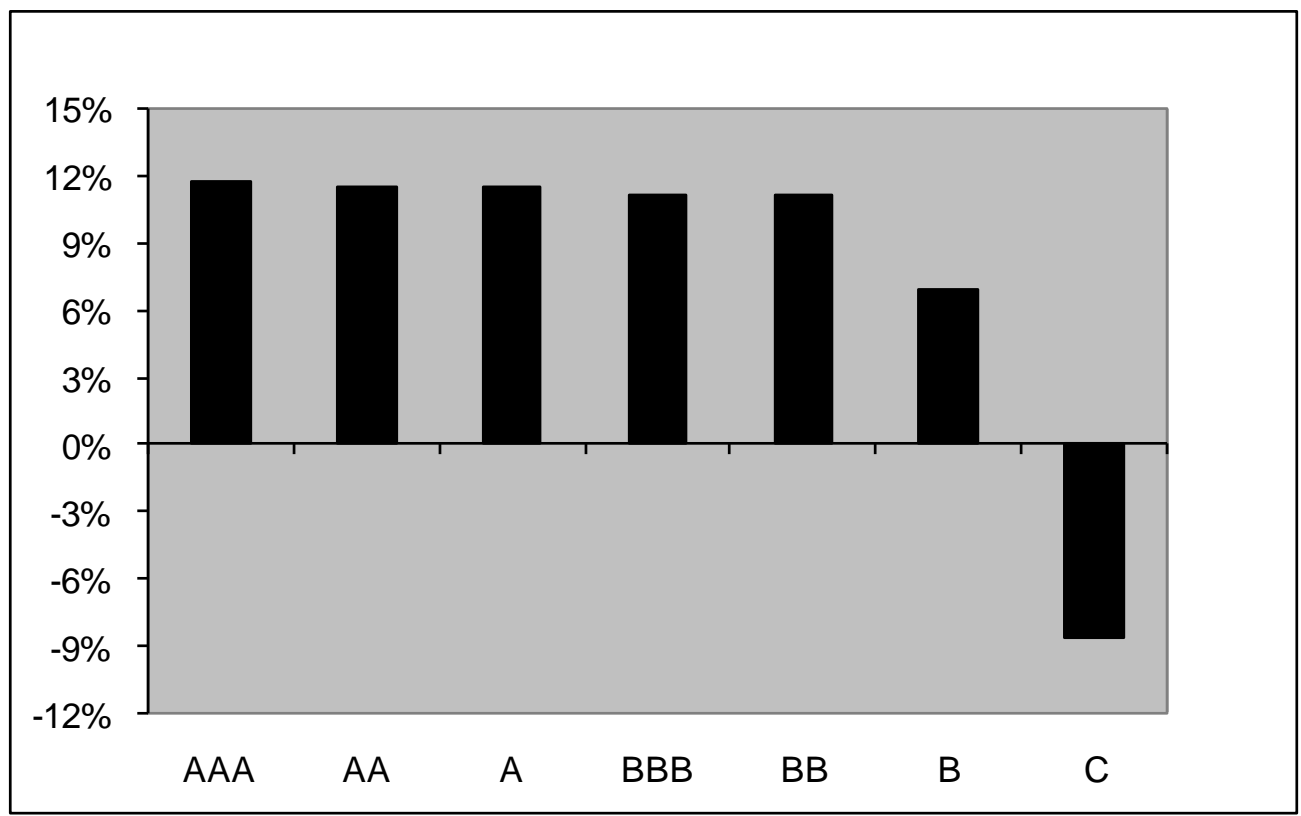

The returns are pretty flat until you get to the signature junk bonds, the Bs, and then it falls precipitously, and the Cs are actually negative. Thus, the equity returns to firms with low financial strength are low, and their debt does not seem to compensate either. High risk, from a financial distress perspective, appears negatively related to returns for Agency-rated companies. When considered in conjunction with the flat to lower returns for B-rated debt, this suggests a negative risk premium for risky company's assets, broadly defined. 


\section{N. Movie Production}

Art DeVany (2003) found that between 1986-99 G-rated movies generated lower volatility and approximately the same returns as R-rated movies, though there was a clear preference towards R-rated movies (over 1000 R-rated movies and only 60 G-rated ones). But movies has a strong pareto distribution, where the mean is much higher than the median or mode. It seems studio executives are generally betting on the next Titanic, because the very highest grossing movies are $\mathrm{R}$ rated.

Figure 9

Movie Gross Return and Volatility by Rating

2015 movies from 1985-96

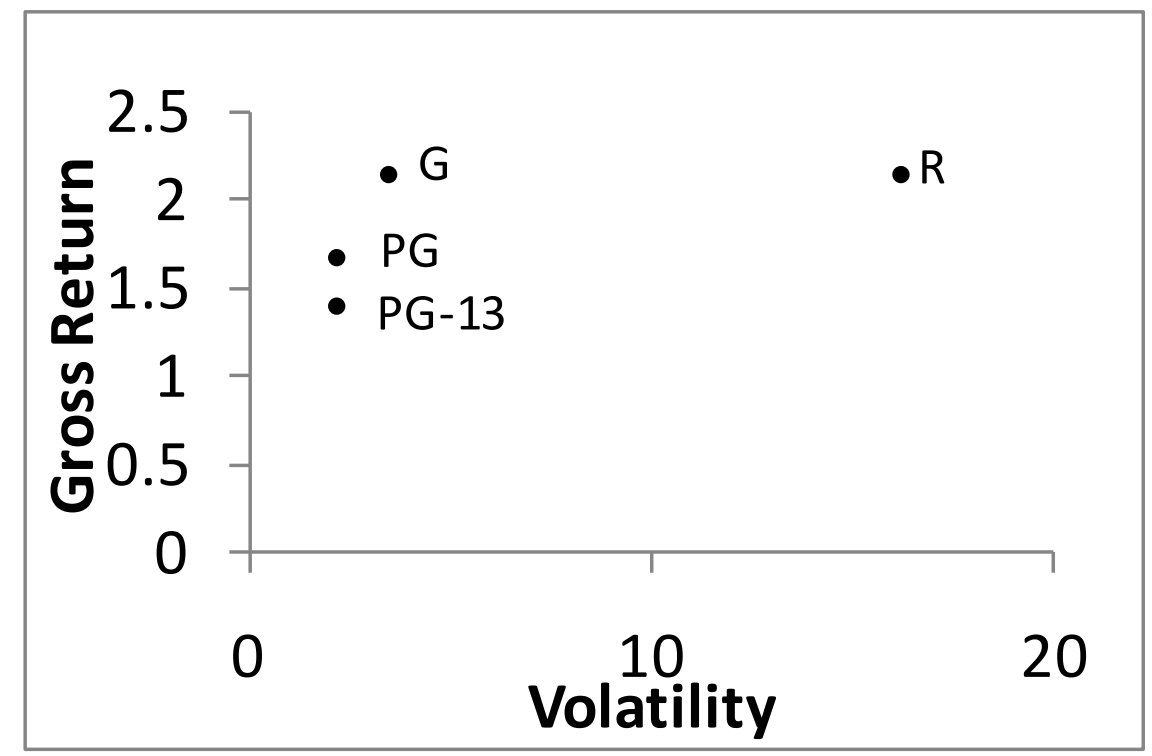

Devany and Walls (1997) 


\section{O. Sports Book}

Bets on high probability-low payoff gambles have high expected value and low probability-high payoff gambles have low expected value. For example, a 1-10 horse having more than a $90 \%$ chance of winning has an expected value of about $\$ 1.03$ (for every $\$ 1$ bet), whereas a 100-1 horse has an expected value of about 14 cents per dollar invested (Hausch, Lo, and Ziemba (1994).

This bias has appeared across many years and across all sizes of race track betting pools. The effect of these biases are that for a given fixed amount of money bet, the expected return varies with the odds level. The favorite long-shot bias is monotone across odds and the drop in expected value is especially large for the lower probability horses. For bets on extreme favorites, there is an positive expected return. For all other bets, the expected return is negative. Ziemba, and Hausch (1984) document the favorite long-shot bias is monotone across odds and the drop in expected value is especially large for the lowest probability horses (worse than 50-1).

\section{P. Lotteries}

The annual per capita lottery expenditure in the US is about $\$ 170$, and the rate of return is about $-47 \%$ per dollar played. It clearly presents a challenge to the idea that people are looking at these games on a risk-return continuum, and motivated the earliest inflected utility functions (Friedman and Savage (1948). These investments clearly cater to what is commonly called those seeking risk, or positive skew. There are two primary characteristics of lotteries. First, poor people play them more, in both relative and absolute terms, than wealthy people. Bhattacharyya and Garret (2006) find that poorer households spend considerably more than wealthier households on lotteries. 
Garrett and Sobel (2004) find the popularity (sales) of lotteries found that average payout (expected return), but the size of the top prize was highly significant. In other words, the $\$ 100$ million super lotto has the most sales even though the probability of winning is so small it basically is outside the realm of intuition (1 in 195 million for the popular Powerball). People who buy lottery tickets seem to prefer those lotteries that offer the worst odds, but the greatest payout. Gambling seems to be totally outside the assumptions of risk aversion, and is the common motivator for Prospect Theory applications.

\section{Q. Total Volatility and Aggregate Volatility and Returns}

The most basic risk models assume that the expected return on an asset is proportional to the expected nondiversifiable variance of the asset: the higher the variance, the higher the expected return (see Merton (1980)). Modern models tend to focus on some abstract thing we don't like, like declines in consumption, wealth, or output, but those bad states are generally coincident with higher volatility, as volatility increases when the economy is doing poorly. In general, researchers document a null relationship between volatility and future returns, some find a negative relationship (Campbell (1987), Whitelaw (1994), Nelson (1991).

Sharpe and Amromin (2005) used survey data, and found investor expectations were totally inconsistent with standard models. They found that when investors have a more favorable assessment of macroeconomic conditions, they tend to expect higher returns. Second, they found that the expectation of more favorable economic conditions has a strong negative effect on expected stock market volatility. A good example of this kind of thinking is a Gallup poll put out by Paine Weber (Graham, Benjamin and Jason Zweig. 2003). In 1998, at the beginning of the stock market boom, they surveyed an expected return of $13 \%$ from investors. After back to back $20 \%+$ returns, when the Nasdaq doubled, investors raised their expectations to $18 \%$ in 
February of 2000, right before the peak. Two years later, after a 50\% correction, and a $50 \%$ rise in the VIX (a measure of expected volatilities), they anticipated only a 7\% expected return. So from a Sharpe ratio perspective, when investors expect a high numerator, they expected a low denominator. They expect 'good' times to be high returns and low volatility, and 'bad' times to be low returns and high volatility.

\section{R. Initial Public Offerings}

An initial public offering has a great deal of uncertainty, especially for an economist wishing to apply a factor sensitivity to it, because there is no historical time series for the equity. One usually applies a factor based on its characteristics, such as size, book/market, and perhaps industry. But without a track record, these assignments are highly uncertain in the Keynesian/Knightian sense. One would expect, given uncertainty aversion, for these stocks to have positive returns to compensate for this uncertainty.

Examining IPOs from 1980-2001, Ritter and Welch (2002) finds the geometric average return for these IPOs five years after issuance are 5.1\% below size and book-to-market matched firms. People who buy IPOs pay a premium, perhaps on the hope of buying the next Yahoo! or Google.

\section{S. Analyst Disagreement}

Differences of opinion should proxy for parameter uncertainty, a perhaps better estimate of risk (see Hansen and Sargent (2001)). Using analysts' earnings forecasts as a proxy for differences of opinion among investors, Karl Diether et al (2002) find the quintile of stocks with the greatest opinion dispersions underperformed a portfolio of otherwise similar stocks. 
Each month, they take stocks and sort them into five groups based on size (market cap), and then within these groups, sort again into quintile based on analyst forecast dispersion, as measured by the ratio of the standard deviation of analyst current fiscal year annual earnings per share forecasts to the absolute value of the mean forecast. They find that the stocks with the higher dispersion in analyst's earnings forecasts earn significantly lower returns than otherwise similar stocks. Specifically, the highest dispersion group had a 9.5\% annual return deficit over the 1980-2002 period.

\section{T. Trading Volume}

Another metric of disagreement is the amount of trading volume in a stock, normalized by its stock volume. On average, if disagreement leads to more transactions as optimists and pessimists take sides, we should see a higher return to these stocks. In the US, since 1997, I created an index of stocks in the top 1500 that had the highest trading volume/shares outstanding, each six months. The annualized geometric return for these high volume stocks was $1.6 \%$, vs $9.7 \%$ for the low volume stocks. The high volume stocks tend to be highly correlated with higher beta portfolio returns, and low volume with low beta stocks.

If one's education was unaware of utility functions one would have to look at these data and say that volatility is inversely correlated with returns. The only clear area that a risk premium appears is in the BBB-AAA spread, the short end of the yield curve, and the equity risk premium. They are exceptions to the rule. Further, in Falkenstein (2009), I note that after adjustments for transaction costs, peso problems, taxes, and several other reasonable adjustments, the average investor's equity premium is probably zero. The theory that metrics of risk such as volatility or covariance is positively correlated with average returns fails 
spectacularly when applied to volatility, movies, beta, developing country equities, aggregate volatility and aggregate returns, gambling, lotteries, options, financial leverage, financial distress, currencies, mutual funds, small businesses, analyst forecast dispersion, IPOs, and futures. These are not minor lacunae, but the heart of the risk-return theory. As a first approximation, volatility should be generally positively correlated with returns if 'priced risk' is to have any meaning in an asset pricing theory.

\title{
II. How a Relative Utility Function Generates Zero Risk Premium
}

The purpose here is to present a model where there is no risk premium in equilibrium. The models presented are simple, but an even simpler example is useful in seeing the driver of this the result. There are two assets, $\mathrm{X}$ and $\mathrm{Y}$, and two states of nature, 1 and 2. An investor faced with asset $\mathrm{X}$ or $\mathrm{Y}$ can see the following returns:

\section{Table II}

\section{Payoffs to Assets $\mathrm{X}$ and $\mathrm{Y}$ in States 1 and 2}

\author{
Total Return Avg. Relative Return
}

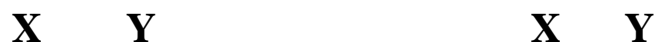

$\begin{array}{rrrrrr}\text { State } 1 & 0 & -10 & -5 & 5 & -5 \\ \text { State 2 } & 20 & 30 & 25 & -5 & 5\end{array}$


As shown in Table II, $\mathrm{Y}$ is conventionally considered riskier, with a 40 point range in payoffs versus a 20 point range for $\mathrm{X}$. Yet on a relative basis, each asset generates identical risk. In State $1, \mathrm{X}$ is a +5 out performer; in State $2, \mathrm{X}$ is a -5 underperformer, and vice versa for asset Y. In relative return space, the higher absolute volatility asset is not riskier; the reader can check this for any example in which the two assets have the same mean absolute payout over the states (i.e., the average for asset $\mathrm{X}$ and asset $\mathrm{Y}$ is the same) The risk in low volatility assets is its losing ground during good times. If $\mathrm{X}$ and $\mathrm{Y}$ are the only two assets in the economy, equivalent relative risk can be achieved by taking on an undiversified bet on $\mathrm{X}$ or $\mathrm{Y}$, which is identical to taking a position on not-Y and not-X. The positions, from a relative standpoint, are mirror images. Buying the market, in this case allocating half of each, meanwhile, generates zero risk.

Everything really flows from this simple insight. Implicitly the equilibrium and arbitrage derives from the fact that when relative portfolio wealth is the argument in the utility function, systematic volatility is symmetric, as the complement to any portfolio subset will necessarily have identical — though opposite signed - relative return. Thus gains from trade can always be made if there is a risk premium.

\section{A. The Arbitrage Model}

Assume an economy with risky assets that are a function of a market factor $r_{m}$. For any investor $i$ who chooses an asset with a specific beta $\beta_{i}$, returns are generated via the factor model

$$
r_{i}=\mu_{\beta_{i}}+\beta_{i} r_{m}
$$


Where $\mu_{\beta_{i}}$ is a constant for an asset with the specific beta $\beta_{i}$, and $r_{m} \sim N\left(\mu_{m}, \sigma_{m}^{2}\right)$. We will assume no idiosyncratic risk from assets, because the gist of this approach is without loss of generality.

The return on the risk-free asset is the constant $r_{f}$. The market price of all assets, risky or risk-free, are assumed equal to 1 , so we are solving for a $r_{f}, \mu_{\beta_{i}}$ and $\mu_{m}$ such that this is an equilibrium. That is, the prices are set to one, but the returns are free parameters.

The market return in this model is the benchmark to which investors compare themselves, just as mutual fund managers typically try to outperform their benchmark. Their objective is to maximize their out performance, subject to minimizing its variance. Define $r_{\text {out }}^{i}$, which is the relative performance of investor $i$ to the market return

$$
r_{\text {out }}^{i}=r_{i}-r_{m}
$$

Here $r_{i}$ is the return on the investor's portfolio with its particular factor loading $\beta_{i}$, and $r_{m}$ is the return on the market. Investors all have the simple objective of maximizing $r_{\text {out }}^{i}$ while minimizing a proportion of its variance, as in

$$
\operatorname{Max} r_{\text {out }}^{i}-a / 2 \sigma_{i}^{2}
$$

Where $\sigma_{i}^{2}=\operatorname{Var}\left(r_{i}-r_{m}\right)$. Substituting equation (1) into (2) generates

$$
r_{\text {out }}^{i}=\mu_{\beta_{i}}+\left(\beta_{i}-1\right) r_{m}
$$

Since $r_{m}$ is the only random variable, the variance of outperformance is just

$$
\sigma_{i}^{2}=\left(\beta_{i}-1\right)^{2} \sigma_{m}^{2}
$$


Equation (5) implies that the beta bet is basically risky to the extent it deviates from the average, in either direction. We can replicate the relevant risk of a stock with a beta of $\beta_{i}, \sigma_{i}^{2}$, via a portfolio consisting of $\beta_{i}$ units of the market portfolio, and borrowing $\left(1-\beta_{i}\right)$ units of the risk-free asset $\left(\operatorname{cost}\right.$ is $\beta_{i}-\left(1-\beta_{i}\right)=1$, same as for the stock, as all assets have a price of 1 by assumption). Arbitrage then implies that these have the same expected returns, so

$$
E\left(\beta_{i} r_{m}+\left(1-\beta_{i}\right) r_{f}\right)=E\left(\mu_{\beta_{i}}+\beta_{i} r_{m}\right)
$$

The LHS of equation (6) is the market portfolio levered $\beta_{i}$ times by borrowing $\left(1-\beta_{i}\right)$ in the risk-free asset in financing, while the RHS is the unlevered $\beta_{i}$ asset portfolio via equation (1). They have the same factor exposure, and cost the same, so they should have the same return in equilibrium. Thus equation (6) implies

$$
\mu_{\beta_{i}}=\left(1-\beta_{i}\right) r_{f}
$$

This allows us to replace the $\mu_{\beta_{i}}$ with $\left(1-\beta_{i}\right) r_{f}$ in equation (4) and leads to the factor model

$$
r_{\text {out }}^{i}=\left(1-\beta_{i}\right) r_{f}+\left(\beta_{i}-1\right) r_{m}
$$

If the degree of risk of relevance to investors is their out performance, $\sigma_{i}^{2}$, the expected return for assets with $\beta=k$ should be the same as those with $\beta=2-k$, because they have the same risk in this environment: $(k-1)^{2} \sigma_{m}^{2}=((2-k)-1)^{2} \sigma_{m}^{2}$. The risk of a $\beta=2$ asset is identical in magnitude to a $\beta=0$ asset, so the expected returns must be the same

$$
E\left(r_{\text {out }}^{i} \mid \beta=k\right)=E\left(r_{\text {out }}^{i} \mid \beta=2-k\right)
$$


Using equation (9) on the equivalence of $2-k$ and $k$ beta assets, and applying the expectations operator, we have

$$
(1-k) r_{f}+(k-1) E\left(r_{m}\right)=(1-(2-k)) r_{f}+((2-k)-1) E\left(r_{m}\right)
$$

The LHS of equation (10) is the expected return on the $\beta=k$ asset, and the RHS is the expected return on the $\beta=2-k$ asset. Solving for $E\left(r_{m}\right)$ we get

$$
E\left(r_{m}\right)=r_{f}
$$

Equations (1), (7) and (11) imply

$$
\begin{aligned}
& r_{i}=r_{f}+\beta_{i}\left(r_{m}-r_{f}\right) \\
& r_{m} \sim N\left(r_{f}, \sigma_{m}\right)
\end{aligned}
$$

Thus no arbitrage, in the sense things equivalent in risk are priced the same (as risk is defined here), generates the traditional CAPM with the significant difference that the expected market return is equivalent to the risk-free rate. Just as the equilibrium model in prior section implies, the expected return on all assets is the same, because $E \beta\left(r_{m}-r_{f}\right)=0 \forall \beta$.

In contrast, a traditional arbitrage model would take from the arbitrage equation (7), and, combined with the market model equation (1), generate the standard factor model

$$
r_{i}=r_{f}+\beta_{i}\left(r_{m}-r_{f}\right)
$$

But now the maximization function reflects the fact that the investor only cares about absolute volatility, not volatility relative to some benchmark.

$$
\operatorname{Max}_{\beta_{i}} r^{i}-a / 2 \beta_{i}^{2} \sigma_{m}^{2}
$$


Substituting equation (13) for $r_{\mathrm{i}}$, the first order condition on equation (14) generates the familiar equation

$$
\beta_{i}=\frac{E\left(r_{m}-r_{f}\right)}{a \sigma_{m}^{2}}
$$

So investor i's optimal $\beta_{i}$ will be equal to the risk premium over the risk aversion coefficient times the market variance. Assuming a representative investor, conventional parameters for this approach of $6 \%$ for the risk premium, 3 for a risk coefficient, and $15 \%$ for market volatility, this implies an equilibrium beta choice of 1 , consistent with an equilibrium where the representative investor holds the market basket. But if, as argued in Falkenstein (2009), the market premium is in effect zero for the average investor, the $\beta_{i}$ choice will be zero, which is not an equilibrium because on average the market beta is 1 by definition and in positive net supply. In the traditional approach, a positive market premium is necessary for investors to hold the market in equilibrium, whereas in a relative risk model, combining equations (3) and (8), we get

$$
\begin{gathered}
\operatorname{Max}_{\beta_{i}}\left(1-\beta_{i}\right) r_{f}+\left(\beta_{i}-1\right) r_{m}-a / 2\left(\beta_{i}-1\right)^{2} \sigma_{m}^{2} \\
\beta_{i}=\frac{E\left(r_{m}-r_{f}\right)}{a \sigma_{m}^{2}}+1
\end{gathered}
$$

Here the optimal choice of $\beta_{i}$ is 1 only if the risk premium is zero (i.e., $\mathrm{E}\left[r_{m}\right]=r_{f}$ ), because risk is uncompensated via arbitrage, and 'risk' can be avoided in this model by choosing a beta of 1. A positive risk premium would induce a desired optimal beta greater than 1 , which would then not be an equilibrium. 
While this is a simple model, it has at its essence no more simplicity than what generates traditional risk premiums. The only difference is whether one puts relative as opposed to absolute wealth in the utility function. Both the absolute and relative risk approach generate the familiar factor pricing model, but in the relative risk approach the risk premium is zero in equilibrium, whereas in the absolute risk approach the risk premium must be positive.

\section{B. Equilibrium with Heterogeneous Investors}

There exists a two-period economy with two identical individuals, $i$ and $-i$. There are two types of assets; one is a risk-free bond that pays off $R_{f}$ with certainty in period 1 . There also exists an equity with a return of $\mathrm{R}_{\mathrm{E}}$, where

$$
R_{E} \sim N\left(\mu, \sigma^{2}\right)
$$

Total wealth for the individual $i$ in period 0 is given by his portfolio of assets.

$$
w_{i}^{0}=\alpha_{E}^{i} R_{E}+\alpha_{f}^{i} R_{F}
$$

$\alpha_{E}^{i}$ and $\alpha_{f}^{i}$ represent the holdings for investor $i$ on the risky and risk-free asset, respectively. Each individual is endowed with $k$ units of wealth, so the budget constraint is

$$
w_{i}^{0} \leq k
$$

Agent $i$ 's utility function is driven by his wealth relative to the other agent (there is no consumption) in an exponential utility function with a risk aversion coefficient $a$.

$$
U_{i}\left(w_{i}^{1}-w_{-i}^{1}\right)=-\exp \left(-a\left\{w_{i}^{1}-w_{-i}^{1}\right\}\right)
$$

As the argument in equation (21) is normally distributed, the individual therefore maximizes the following function 


$$
\underset{\alpha_{E}^{i}, \alpha_{f}^{i}}{\operatorname{ar}} \mathrm{E}\left(w_{i}^{1}-w_{-i}^{1}\right)-\frac{a}{2} \operatorname{Var}\left(w_{i}^{1}-w_{-i}^{1}\right)
$$

Note his utility is strictly increasing in his own wealth, $w_{i}^{1}$, and strictly decreasing in the wealth of the other investor, $w_{-i}^{1}$, reflecting the pure envy in this economy. Also, the variance of his difference from this other investor negatively impacts his utility in an amount proportional to his coefficient of risk aversion, $a$. As there is no consumption, the agent can do nothing to affect his period 0 wealth, so his relevant decision only concerns optimizing for period 1 . His utility is strictly increasing in $\alpha_{E}$ and $\alpha_{f}$, so his budget constraint holds with equality, from equations (19) and (20) we have

$$
\alpha_{f}^{i}=k-\alpha_{E}^{i}
$$

Substituting for $w_{i}^{1}$ and $w_{-i}^{1}$ and applying the expectations operator, this problem expands

to

$$
\operatorname{Max}_{\alpha_{E}^{i}} \alpha_{E}^{i} \mu+\left(k-\alpha_{E}^{i}\right) R_{f}-\alpha_{E}^{-i} \mu-\left(k-\alpha_{E}^{-i}\right) R_{f}-\frac{a \sigma^{2}}{2}\left(\alpha_{E}^{i}-\alpha_{E}^{-i}\right)^{2}
$$

Taking the first order conditions with respect to $\alpha_{E}^{i}$, we have

$$
\mu=R_{f}+a \sigma^{2}\left(\alpha_{E}^{i}-\alpha_{E}^{-i}\right)
$$

Since each agent is identical, in equilibrium each agent holds the same amount

$$
\alpha_{E}^{i}=\alpha_{E}^{-i}
$$

Given equations (26) and (25), we have

$$
\mu=R_{f}
$$


And as there is no $\beta$, and no risk aversion coefficient $a$ in equation (27), the same expected return holds regardless of its sensitivity to the market factor $r_{m}$, or the volatility of the market, $\sigma_{m}$. The returns on all assets - low risk, high risk, no risk — are the same. Risk does not affect return in equilibrium.

The model allows a strict comparison to the traditional case, where there is no peer comparison in the argument of the utility function. It can be shown that if instead a relative utility function a traditional von Neumann-Morgenstern utility function based on absolute wealth is used, such as

$$
U_{i}\left(w_{i}^{1}\right)=-\exp \left(-a w_{i}^{1}\right)
$$

Then using the same reasoning above generates the traditional result that riskiness affects returns, specifically,

$$
\underset{\alpha_{E}^{i}, \alpha_{f}^{i}}{\operatorname{ar}} \mathrm{E}\left(w_{i}^{1}\right)-\frac{a}{2} \operatorname{Var}\left(w_{i}^{1}\right)
$$

Substituting for $w_{i}^{1}$

$$
\operatorname{Max}_{\alpha_{E}^{i}} \alpha_{E}^{i} \mu+\left(k-\alpha_{E}^{i}\right) R_{f}-\frac{a \sigma^{2}}{2}\left(\alpha_{E}^{i}\right)^{2}
$$

Differentiating with respect to $\alpha_{E}^{i}$, we have the traditional results that the return on risky assets is greater than for risk-free assets, return is strictly increasing in the volatility of the market ( $\sigma^{2}$ ), the asset's sensitivity to this volatility ( $\square$ ), the risk aversion coefficient $(a)$, and the amount of the risky asset the individuals holds $\left(\alpha_{E}^{i}\right)$.

$$
\mu=R_{f}+a \sigma^{2} \alpha_{E}^{i}
$$


This is the standard result as in Merton (1980), that the expected return of the nondiversifiable risky asset is a linear function of its variance. In both the traditional and the relative risk scenarios above, identical optimizing agents hold the same amount of each asset because they are identical; however, asset prices are different in the two scenarios, so that there exists a zero risk-return relation when individuals have relative status utility functions, while in the traditional case higher non-diversifiable volatility increases the expected return for risk. The intuition is that in the traditional approach, non-diversifiable risks cannot be diversified away, variance in wealth diminishes expected utility, and so this undesired aspect of an asset lowers its price to make it comparable in marginal utility per dollar with the safe asset. In contrast, in the relative status model, risk can be avoided entirely by choosing symmetric portfolios, which individuals do in equilibrium in order to maximize their joint utility.

\section{A Discrete Model}

First, we set up the model using identical agents, each with standard utility functions. This will both make the introduction of the final assumptions more understandable, and also highlight how this approach is consistent with traditional results when one uses traditional assumptions.

Consider a model with two agents. Each agent has an identical, standard, CRRA utility function. So that

$$
\begin{aligned}
U_{i}(W) & =\frac{W^{1-\phi}}{1-\phi} \text { for } \phi>0, \phi \neq 1 \\
& =\ln W \text { for } \phi=0
\end{aligned}
$$

The agents' utility is only a function of total wealth in period 1 , the period when uncertainty is resolved. 
There are 2 assets, a safe asset with no volatility and no net return (gross return equal to 1), and an asset with volatility and a mean net return potentially different from zero. The asset has two states, up and down, which are realized in the next period (there are only two periods, 0 and 1). The risky asset has a gross return of R:

$$
\begin{array}{lll}
R(\text { up }) & =1+\sigma & \text { w/ prob }=p \\
\mathrm{R}(\text { down }) & =1 /(1+\sigma) & \text { w/ prob }=1-p \\
\sigma>0 & &
\end{array}
$$

Note $\mathrm{R}($ down $)=\mathrm{R}(\text { up })^{-1}$. In this way, if $p=0.5$, the geometric mean expected return is zero for any $\sigma$ because the expected geometric return is merely $E[R]=R(u p)^{p} R(\text { down })^{1-p}$, or $E[R]=(1+\sigma)^{p}(1+\sigma)^{p-1}=(1+\sigma)^{2 p-1}$ The return is increasing in probability of the up state $p$, as the higher this probability, the higher the expected return. I will call the $\sigma$ the volatility, which corresponds roughly to the volatility of the percent logarithmic return.

The geometric mean return is simply

$$
\mu_{g}=\exp ((2 p-1) \cdot \ln (R))
$$

While the geometric standard deviation is

$$
\sigma_{g}=\sqrt{p(\ln (R))^{2}+(1-p)(\ln (R))^{2}-\left(\ln \left(\mu_{g}\right)\right)^{2}}
$$

(as this is a binary random variable it is technically not the standard deviation, which is often thought of as the volatility of $\log$ returns).

For the risky asset, the parameters $p$ and $\sigma$ allow us to analyze the mean and volatility of the asset return independently. 
In the initial period, each agent has 2 units of wealth to allocate between the risky and risk-free asset, so that their budget constraint in period zero is

$$
\alpha_{r f}^{i}+\alpha_{E}^{i} \leq 2 \forall i
$$

Where $\alpha_{j}^{i}$ is the investment of agent $i$ in asset $j$ (the risk free, or equity asset E). Thus, each agent when applying her total wealth to each of the assets, her wealth in period 1 (after uncertainty is revealed) is simply

$$
W^{i}=\alpha_{r f}^{i}+\alpha_{E}^{i} R
$$

Given each agent's budget constraint, each agent basically has one choice, how much to invest in the risky asset $\mathrm{E}$, because as their utility is strictly increasing in wealth, the budget constraint holds with equality. This implies that the safe asset will have the residual wealth allocation $\alpha_{r f}^{i}=2-\alpha_{E}^{i}$.

Thus, total wealth in the second period can be rewritten more simply as:

$$
W^{i}=\left(2-\alpha_{E}^{i}\right)+\alpha_{E}^{i} R
$$

Each asset is has a supply equal to 2 , so that

$$
\alpha_{j}^{i}+\alpha_{j}^{-i}=2 \forall j
$$

As there is one asset, each with two states, the wealth of an agent in period 1 is the following

$$
W_{i}(s)=\left(2-\alpha_{E}^{i}\right)+\alpha^{i} R\left(\alpha_{E}^{i}\right)
$$


Thus $W_{\mathrm{i}}(\mathrm{s})$ is a scalar representing agent i's wealth in a particular state. Given his allocation to the risky asset, this determines his total wealth in period 1 . His expected wealth is thus

$$
E U_{i}=p \cdot \frac{\left[\left(2-\alpha_{E}^{i}\right)+\alpha_{E}^{i} R(u p)\right]^{1-\phi}}{1-\phi}+(1-p) \cdot \frac{\left[\left(2-\alpha_{E}^{i}\right)+\alpha_{E}^{i} R(\text { down })\right]^{1-\phi}}{1-\phi}
$$

The first-order conditions to this problem are that the derivative for each agent, with respect to their choice of wealth allocated to the risky asset, must be zero in equilibrium. That is,

$$
\frac{\partial E U_{i}}{\partial \alpha_{E}^{i}}=0
$$

Subject to the clearance of supply and demand (equation 39). The second order conditions are simply that the second derivative for maximizing utility are negative, i.e.,

$$
\frac{\partial E U_{i}^{2}}{\partial w_{2}^{i}}<0
$$

Given the utility function, and definition of wealth, we have the first order agent maximizing condition as

$$
\begin{aligned}
& \frac{\partial E U_{i}}{\partial \alpha_{E}^{i}}=p \cdot\left[\left(2-\alpha_{E}^{i}\right)+\alpha_{E}^{i} R(u p)\right]^{-\phi}(R(\text { up })-1)+ \\
& (1-p) \cdot\left[\left(2-\alpha_{E}^{i}\right)+\alpha_{E}^{i} R(\text { down })\right]^{-\phi}(R(\text { down })-1)
\end{aligned}
$$

And the second order condition as

$$
\begin{aligned}
& \frac{\partial E U_{i}}{\partial \alpha_{E}^{i}}=-\phi p \cdot\left[\left(2-\alpha_{E}^{i}\right)+\alpha_{E}^{i} R(u p)\right]^{-\phi-1}(R(\text { up })-1)^{2}- \\
& \phi(1-p) \cdot\left[\left(2-\alpha_{E}^{i}\right)+\alpha_{E}^{i} R(\text { down })\right]^{-\phi-1}(R(\text { down })-1)^{2}
\end{aligned}
$$


With positive $\sigma, W^{i}>0$ for each state, the second order condition is always negative which implies solving equation (44) generates a maximum for each agent. If equation (44) is satisfied for each agent, and markets clear, this is an equilibrium. In this case, agents are identical, so $\alpha^{i}=\alpha^{-i}$, which trivially must be 1 for each agent (because $\alpha^{i}+\alpha^{-i}=2$ ).

Given $R($ up $)=1+\sigma$ and $R($ down $)=(1+\sigma)^{-1}$, we can solve for $\mathrm{p}$ analytically in this case

$$
p=\frac{(1+\sigma)^{\phi}}{(1+\sigma)^{\phi}+(1+\sigma)}
$$

Plugging $\mathrm{p}$ into the expected return function, we get the following expected returns (equation (34)) as a function of $\phi$ and $\sigma$ displayed in figure 10.

Note this approach generates the standard result, that higher volatility $(\sigma)$ assets are associated with higher expected returns on those assets, and this relationship is greater the greater the degree of risk aversion, $\phi$.

\section{Figure 10}

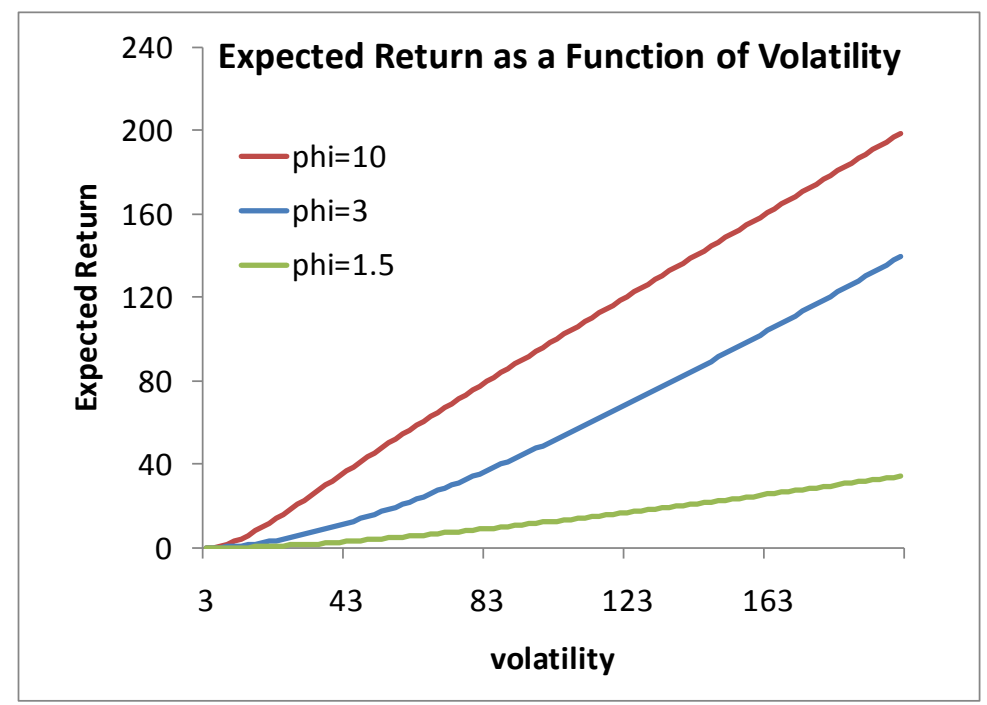


We see that as volatility rises, at first the expected return needed to compensate is relatively small, but then this asymptotes to a linear function, which approaches 1 as $\phi$ or $\square$ goes to infinity. Varying $\phi$ generates higher returns along this function, the higher the risk aversion, the higher the expected return consistent with an equilibrium.

It is interesting to note that the ratio of the expected return over the volatility increases to a constant, so that at very low level of volatility, the required return premium for this risky asset is relatively low, but eventually asymptotes at a constant less than 1 . This is because at low levels of volatility, the relative impact on total wealth is so low it does not span a great deal of the concave utility function. At local dimensions, the curvature of the utility function is weak, and so, there is little difference between the mean utility from the two states, and receiving the certainty equivalent outcome.

\section{Figure 11}

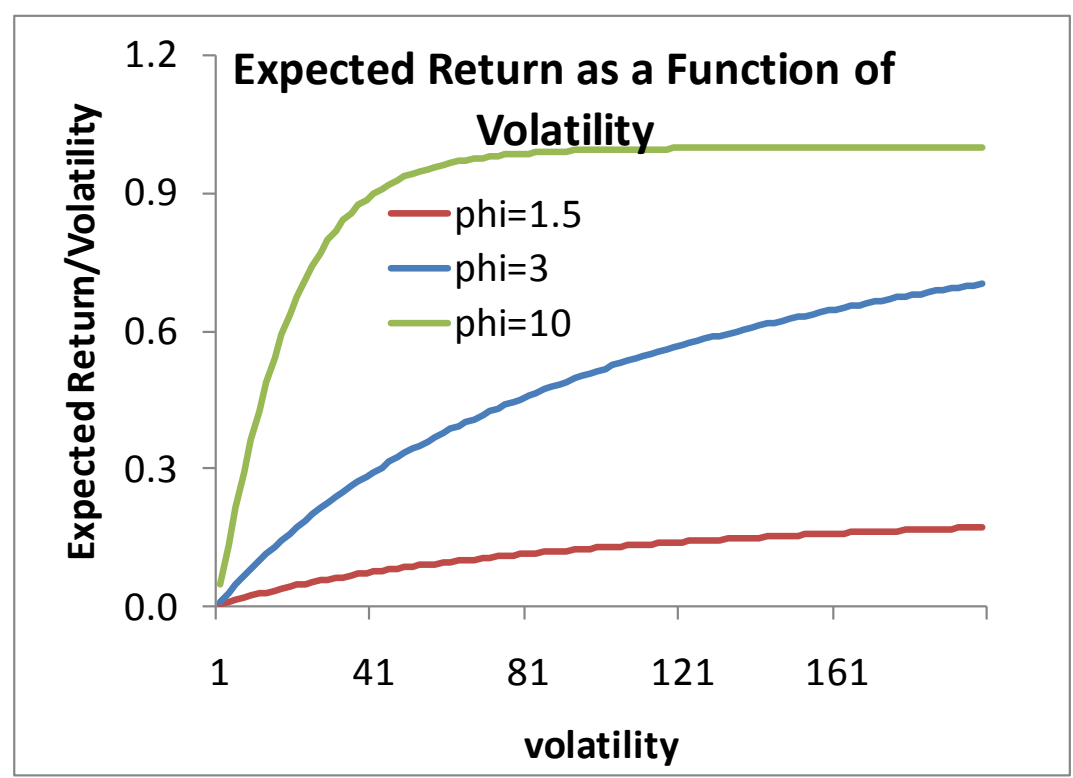




\section{The Discrete Case with Relative Utility}

The first adjustment to the standard model is to use a relative utility function. Now, instead of an agent only caring about his wealth, he cares about his wealth relative to the other agent. To make this analytically tractable I use the ratio of wealth (solving for equilibrium numerically with differences yields similar results). Thus, his utility function is now

$$
\begin{gathered}
U_{i}\left(W^{i}, W^{-i}\right)=\frac{\left(\frac{W^{i}}{W^{-i}}\right)^{1-\phi}}{1-\phi} \text { for } \phi>0, \phi \neq 1 \\
=\ln \left(\frac{W^{i}}{W^{-i}}\right) \text { for } \phi=0
\end{gathered}
$$

As otherwise both agents are identical, have the same beliefs, and markets must clear, trivially $\mathrm{W}^{\mathrm{i}}=\mathrm{W}^{-\mathrm{i}}$, for whatever $\alpha_{E}^{i}$ and so the utility function is in this sense degenerate where the argument is always 1 in equilibrium. Yet, one can still calculate marginal utilities and determine the equilibrium parameters to this equilibrium. That is, the final equilibrium is degenerate because in this example, identical agents will always generate identical wealth allocation, and so have identical relative wealth and utility in every state. Yet this is an equilibrium outcome, and marginal utilities, and therefore prices and returns, are different in equilibrium.

Consider the case where $\alpha_{E}^{-i}=1$, which is the equilibrium given these agents are identical. Though the resulting solution in this case is degenerate and uninteresting, the marginal utilities suggest an interesting contrast to the absolute utility case. For the absolute utility scenario, the derivative with respect to $\alpha_{E}^{i}$ for an agent at equilibrium (where $\alpha_{E}^{-i}=1$ ) is

$$
\left.\frac{\partial U(a b s)}{\partial \alpha_{E}^{i}}\right|_{\alpha_{E}^{i}=1}=(1-p)\left(R^{-1}-1\right)\left(2-\alpha_{E}^{i}+\alpha_{E}^{i} R^{-1}\right)^{-\phi}+p(R-1)\left(2-\alpha_{E}^{i}+\alpha_{E}^{i} R\right)^{-\phi}
$$


Where $\mathrm{R}=\mathrm{R}($ up $)=1+\mathrm{s}$ and $\mathrm{R}^{-1}=\mathrm{R}($ down $)=(1+\mathrm{s})^{-1}$. Whereas in the relative utility case, the derivative is

$$
\left.\frac{\partial U(r e l)}{\partial \alpha_{E}^{i}}\right|_{\alpha_{E}^{i}=1}=\frac{(1-p)\left(R^{-1}-1\right)\left(\frac{2-\alpha_{E}^{i}+\alpha_{E}^{i} R^{-1}}{R^{-1}-1}\right)^{-\phi}}{R^{-1}+1}+\frac{p(R-1)\left(\frac{2-\alpha_{E}^{i}+\alpha_{E}^{i} R}{R-1}\right)^{-\phi}}{R+1}
$$

The derivative for each case is decreasing in $\alpha_{E}^{i}$. For the case $\mathrm{p}=0.5$, the expected net geometric return is zero irrespective of $\mathrm{R}$ for the relative utility case, whereas the derivative is negative in the absolute utility case (equation (48)). For $\mathrm{R}>1$, only at some $\mathrm{p}>0.5$ is equation (49) zero with respect to $w$ in equilibrium (i.e., where each agent holds $\alpha_{E}=1$ ). In contrast, in the relative utility case (equation (49)), $\mathrm{p}>0.5$ causes the derivative of utility with respect to $\alpha_{E}^{i}$ to be positive in equilibrium, which means it cannot be an equilibrium.

This is because in a relative utility framework, the equilibrium where each agent holds the same portfolio has zero volatility for the argument in the agent's utility function. He needs no extra incentive to hold positive levels of the volatile equity asset, because to do otherwise is risky, and would require compensation. If each agent is holding one unit of the risky asset, a positive expected return for the relative utility scenario implies each agent would want to hold relatively more of the risky asset, which is not an equilibrium. In contrast, each agent in the absolute utility case must be induced to hold the risky asset via the higher return in equilibrium.

Thus, expected return, as a function of volatility, in the relative utility framework, is simply zero for all levels of volatility and all risk aversion parameters.

\section{E. Relative Utility and Heterogeneous Beliefs}


The assumptions needed for rational agents to disagree are beyond the scope of this paper. I will simply assume that people do disagree (though, see Aragones, Gilboa, Postlewaite, and Schmeidler (2005) as to why this can be rational). That is, some people are more optimistic about mean returns than others. Let us consider the relative utility scenario where one agent has higher expected return than the other on the risky asset.

Specifically, the expected return for each agent will contain different values of $p$, such that a higher $\mathrm{p}$, the probability of the up state, which generates a higher expected return. Thus, we will assume each agent has different $p$. An equilibrium that holds where one agent thinks assets will rise more than the other will necessarily imply that one agent will hold more of this asset in equilibrium. In equilibrium, the asset market clears (supply of the risky and riskless asset equals 2), and the derivative of each agent's utility with respect to their allocation to the risky asset is zero.

This scenario complicates the analysis, because not only does each agent think that $p$ (and thus $\mathrm{E}(\mathrm{R})$ ) is different, but this affects the perceived wealth of the other agent too. Thus, we will assume agents disagree on expected returns, but not that each agent is so boundedly rational that they do not apply their expectation for the risky asset to the other agent as well. Thus, for each agent, we have

$$
W(s)=2-\alpha_{E}^{i}+\alpha_{E}^{i} R(s)
$$

$R(s)$ is the same for each agent. But $p$, which determines the expected return, is not, so agent $i$ sees 


$$
\begin{aligned}
& W(\text { up } ; i)=2-\alpha_{E}^{i}+\alpha_{E}^{i} R \quad \text { w/ } p r o b=\mathrm{p}_{i} \\
& W(\text { down } ; i)=2-\alpha_{E}^{i}+\alpha_{E}^{i} R^{-1} \text { w/ prob }=1-\mathrm{p}_{i}
\end{aligned}
$$

Now the utility function for each individual is

$$
U_{i}\left(W^{i}, W^{-i}\right)=\frac{\left(\frac{W^{i}}{W^{-i}}\right)^{1-\phi}}{1-\phi}
$$

This implies the expected utility is just:

$$
U_{i}\left(W^{i}, W^{-i} ; p_{i}\right)=p_{i} \frac{\left(\frac{2-\alpha_{E}^{i}+\alpha_{E}^{i}(1+\sigma)}{2-\alpha_{E}^{-i}+\alpha_{E}^{-i}(1+\sigma)}\right)^{1-\phi}}{1-\phi}+\left(1-p_{i}\right) \frac{\left(\frac{2-\alpha_{E}^{i}+\alpha_{E}^{i}(1+\sigma)^{-1}}{2-\alpha_{E}^{-i}+\alpha_{E}^{-i}(1+\sigma)^{-1}}\right)^{1-\phi}}{1-\phi}
$$

In equilibrium agents are maximizing their utility, the derivative of equation (53) is simply

$$
\frac{\partial U_{i}}{\partial \alpha_{E}^{i}}=p_{i} \sigma \frac{\left(\frac{(\sigma+1) \alpha_{E}^{i}-\alpha_{E}^{i}+2}{(\sigma+1) \alpha_{E}^{-i}-\alpha_{E}^{-i}+2}\right)^{1-\phi}}{(1+\sigma) \alpha_{E}^{i}-\alpha_{E}^{i}+2}+\left(1-p_{i}\right) \frac{\left((\sigma+1)^{-1}-1\right)\left(\frac{(\sigma+1)^{-1} \alpha_{E}^{i}-\alpha_{E}^{i}+2}{(\sigma+1)^{-1} \alpha_{E}^{-i}-\alpha_{E}^{-i}+2}\right)^{-\phi}}{(1+\sigma) \alpha_{E}^{i}-\alpha_{E}^{i}+2}=0
$$

We can assess the effects heterogeneous beliefs by looking at how the expected returns for each agent are affected by varying the equilibrium choices of the risky asets. That is, given equation (53), we know that $\alpha_{E}^{-i}=2-\alpha_{E}^{i}$, and by adjusting these relative weights, it is consistent with different expectations for the two agents. Using the two equations from the agent's maximization, we can solve for $\mathrm{p}_{\mathrm{i}}$ and $\mathrm{p}_{-\mathrm{i}}$, and the resulting different expected returns from equation (34). The results are in figure 13 below. 


$$
p_{i}=-\frac{\left(\alpha_{E}^{-i} \sigma+2\right)\left(\frac{\alpha_{E}^{i} \sigma+2}{\alpha_{E}^{-i} \sigma+2}\right)^{\phi}}{\left(\alpha_{E}^{-i} \sigma-2 \sigma-2\right)\left(\frac{\alpha_{E}^{i} \sigma-2 \sigma-2}{\alpha_{E}^{-i} \sigma-2 \sigma-2}\right)^{\phi}+\left(-\alpha_{E}^{-i} \sigma-2\right)\left(\frac{\alpha_{E}^{i} \sigma+2}{\alpha_{E}^{-i} \sigma+2}\right)^{\phi}}
$$

Figure 13

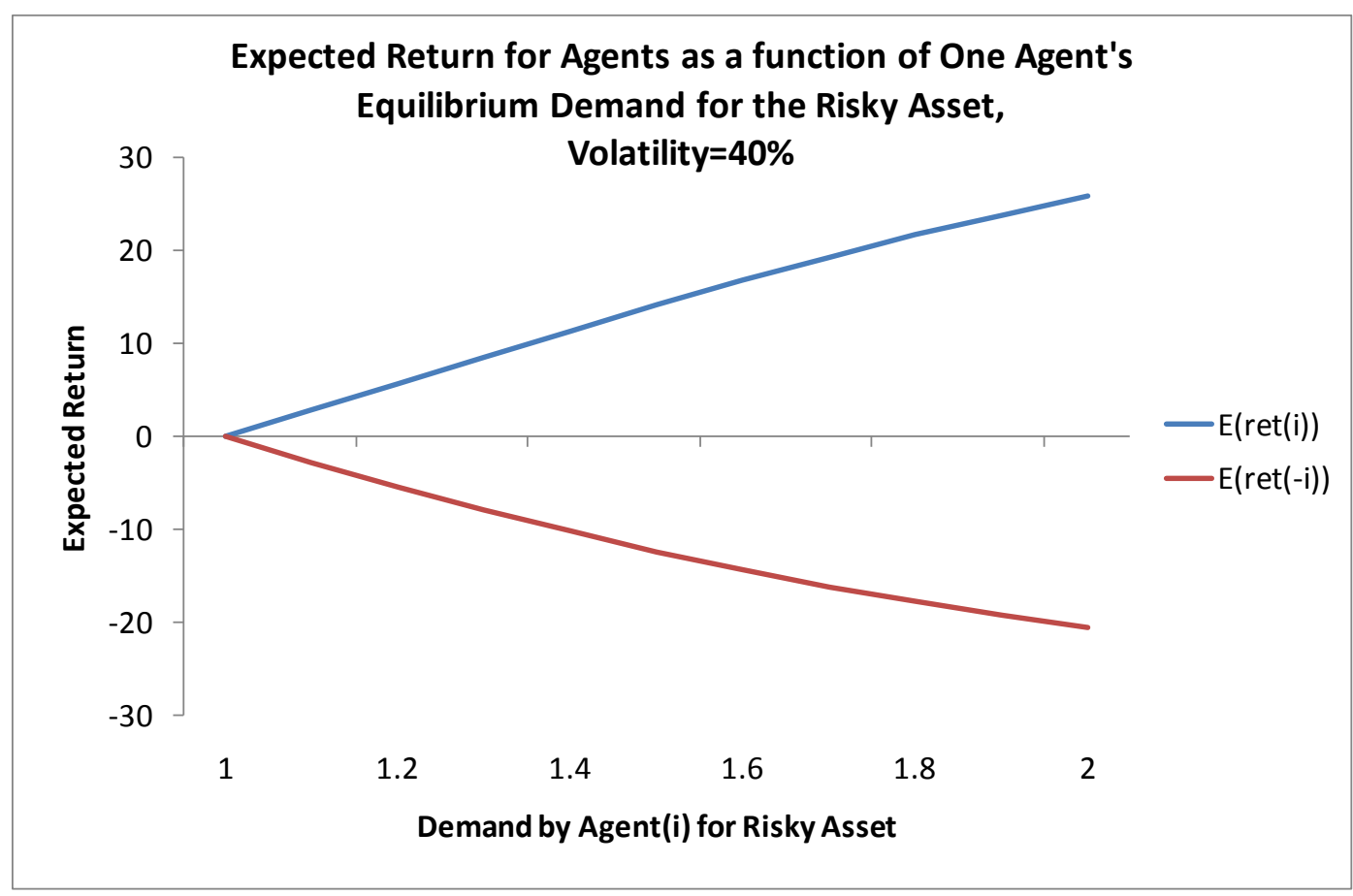

If we increase the risk aversion parameters, or the volatility of the risky asset is higher, these expected returns diverge at a faster rate.

An equilibrium where the agents hold differing amounts can be an equilibrium if they have, basically, symmetrically different expected returns, in this model, as manifested by their differing beliefs about the probability of the good, up, state. The optimist will hold relatively more than the pessimist, the more so the more their expected returns diverge.

The example is simple, but it is an equilibrium using a basic structure that accommodates the standard implications from theories about risk and return. The different implications--zero or 
negative risk premiums--comes from having a relative utility function, and allowing for heterogeneous beliefs. To the extent people disagree, the optimists will hold more of the risky asset than the pessimists. Applying this to our empirical puzzles in section 1 we see that in general, the lack of a return for risk may be due to mere relative utility. The lower return as a function of asset volatility, which appears to occur for the highest volatility stocks, could be from the amenability of these highly volatile stocks to delusional optimists. Those without such delusions, the realists, accept lower-than-average, even negative, returns on these assets--even when they hold them in positive amounts--because basically they pay a risk premium in opportunity cost to offset the 'risk' from deviating from the other agent's wealth.

\section{Conclusion}

The idea that risk is priced is highly intuitive, and implied by globally concave utility functions, which are also highly intuitive as a general rule. Yet the empirical support for a priced risk premium is absent across a large spectrum of investable assets (this excludes catastrophic insurance premium which are outside this analysis). The empirical anomalies to the high riskhigh return hypothesis are not exceptions to a general tendency: There is no general tendency within a variety of investments, such as equities, individual equity options, most of the yield curve, high yield corporate and bankrupt bonds, mutual funds, commodities, small business owners, movies, lottery tickets, and horse races. It is possible the equity premium is actually zero after suitable adjustments for transaction costs and selection biases, and the other two prominent examples of a positive risk-return tradeoff — the short end of the yield curve, the spread on investment grade bonds - do not generalize when extended in the 'risk' spectrum for these asset classes. 
As Mark Rubinstein says about the CAPM and its extensions:

More empirical effort may have been put into testing the CAPM equation than any other result in finance. The results are quite mixed and in many ways discouraging. . . . At bottom . . . the central message of the CAPM is this: Ceteris paribus, the prices of securities should be higher (or lower) to the extent their payoffs are slanted toward states in which aggregate consumption or aggregate wealth is low (or high).... The true pricing equation may not take the exact form of the CAPM, but the enduring belief of many financial economists is that, whatever form it takes, it will at least embody this principle (Rubinstein (2006)).

The current consensus is that evidence for any robust risk factor is weak at best, yet anticipates a refinement subtle enough to escape notice for 40 years, yet still strong enough to explain these data, implying investors currently recognize and price this undiscovered metric.

Diether et al (2002), in their paper on analyst uncertainty and returns, note higher estimate dispersion is positively related to Beta, volatility, earnings variability, yet, because the returns go the wrong way (lower return for higher volatility), they note "our results clearly reject the notion that dispersion in forecasts can be viewed as a proxy of risk". Thus, in spite of being correlated with all things intuitively risky, like beta, volatility, and size, but uncorrelated with value or momentum, the correlation with returns suggests to these researchers that analyst uncertainty cannot be correlated with risk, because the one thing they know about risk, is that it is positively correlated with returns.

The belief that risk, properly measured, must be positively related to returns is very deep among academics. Risk is supposedly not only important and everywhere, but subtle, requiring that investors implicitly have skills similar in sophistication and imprecision to what is needed to 
distinguish between a good and great wine. As an alternative, the irrelevance of risk to return is implied by a status-conscious investor benchmarking himself against others, and holds in both a utility and arbitrage argument. Risk is simply allocating an 'unusual' amount of wealth to any asset that would generate a significant deviation from the market portfolio.

The standard assumption that relevant volatility is absolute wealth may be a good normative theory, but a relative wealth orientation generates a more accurate positive theory, and its assumption is generally considered more accurate by those doing research on the essence of subjective well-being (see Falkenstein (2009)). That is, happiness seems unaffected by large increases in wealth across developed countries, and over time in these countries (the Easterlin Paradox (1974)). A relative status orientation can be efficient, as modeled by Rayo and Becker (2007) or Pesendorfer (1995) The relative status utility function generates a more accurate description of the world.

A relative-status oriented utility function generates a factor model consistent with the familiar CAPM and APT models, except the risk premiums are zero. Beta is still descriptive of relative volatility, and generates normative predictions for volatility minimization. However, there is no robust cross-sectional return to any $\beta$, no upward sloping security market line. The portfolio optimization algorithm for an investor with typical preferences is trivial and mimics practice: allocate assets to the standard categories of conventional wisdom, because this minimizes relative wealth volatility and maximizes returns. The idea that nondiversifiable risk is not priced because it is unnecessary is augmented, so that diversifiable risk is also not priced because it too is unnecessary in the sense of avoiding deviations from the average portfolio. As the saying goes, one has to take risk to generate high returns, but there is no greater expected return merely for taking risk of any sort. 


\section{References}

Altman, Edward and William Stonberg, 2006, The Market in Defaulted Bonds and Bank Loans, Journal of Portfolio Management, Summer.

Altman, EI, and G Bana. 2004. Defaults and returns on high-yield bonds. Journal of Portfolio Management

Amromin, Gene, and Steven A. Sharpe. 2005. From the Horse's Mouth: Gauging Conditional Expected Stock Returns from Investor Survey: SSRN.

Ang, A, Rj Hodrick, Y Xing, And X Zhang. 2006. The cross-section of volatility and expected returns. The Journal of Finance 61 (1):259-299.

Aragones, Enriqueta, Itzhak Gilboa, Andrew Postlewaite, and David Schmeidler, 2005. FactFree Learning. American Economic Review. 95(5): 1355-1368.

Bhattacharyya, N. and Thomas A. Garrett, 2006. Why People Choose Negative Expected Return Assets-An Empirical Examination of a Utility Theoretic Explanation (Federal Reserve Bank of St. Louis).

Black, Fischer. 1976. The Pricing of Commodity Contracts. Journal of Financial Economics 3: 167-79.

Black, Sandra E. 1999. Do Better Schools Matter? Parental Valuation of Elementary Education The Quarterly Journal of Economics, Vol. 114, No. 2 (May, 1999), pp. 577-599

Brunnermeier, MK, S Nagel, and LH Pedersen. 2008. Carry trades and currency crashes. NBER Macroeconomics Annual.

Campbell, J. Y. 1987. Stock returns and the term structure. Journal of Financial Economics 18 (2):373-399.

Campbell, John. 2000. Asset Pricing at the Millennium. Journal of Finance. 55(4): 1515-1568.

Carhart, MM. 1997. On persistence in mutual fund performance. Journal Of Finance 52:57-82.

Coval, JD, and T Shumway. 2001. Expected option returns. The Journal of Finance 56 (3):9831009.

Dahlquist, Magnus, and Ravi Bansal. 2002. Expropriation Risk and Return in Global Equity Markets: SSRN.

Dai, Q, and KJ Singleton. 2002. Expectation puzzles, time-varying risk premia, and affine models of the term structure. Journal of Financial Economics 63 (3):415-441.

De Vany, AS. 2003. Hollywood Economics: How Extreme Uncertainty Shapes the Film Industry: Routledge.

DeVany, A, and D. Walls. 1997. The Market for Motion Pictures: Rank, Revenue, and Survival. Economic Inquiry. 35. 
Dichev, Ilya, 1998, Is the Risk of Bankruptcy a Systematic Risk? Journal of Finance 53,

Diether, KB, CJ Malloy, and A Scherbina. 2002. Differences of opinion and the cross section of stock returns. The Journal of Finance 57 (5):2113-2141.

Dimson, Elroy, Marsh, Paul and Staunton, Mike. 2006. The Worldwide Equity Premium: A Smaller Puzzle. AFA 2008 New Orleans Meetings.

Easterlin, RA. 1974. Does economic growth improve the human lot? Some empirical evidence. Nations and Households in Economic Growth: Essays in Honor of Moses Abramovitz:89125.

Erb, C.B., Cr Harvey, And Te Viskanta. 1995. Country risk and global equity selection. Journal of Portfolio Management 21 (2):74-83.

Falkenstein, Eric. 1994. Mutual Funds, Idiosyncratic Risk, and Asset Returns. Dissertation. Northwestern University.

Falkenstein, Eric. 2009. Finding Alpha: The Search for Alpha when Risk and Return Break Down. Wiley Finance.

Fama, E. and Farber, A. 1979. Money, Bonds, and Foriegn Exchange. The American Economic Review. 69 (4):639-49.

Fama, E. and French, K. 1992. The cross-section of expected stock returns,. Journal of Finance. 47: $427-67$

Friedman, M, and LJ Savage. 1948. The utility analysis of choices involving risk. The Journal of Political Economy 56 (4):279.

Garrett, TA, and RS Sobel. 2004. State lottery revenue: the importance of game characteristics. Public Finance Review 32 (3):313.

George Tita, Trica Petras, and Robert Greenbaum 2006 Crime and Residential Choice: A Neighborhood Level Analysis of the Impact of Crime on Housing Prices. Journal of Quantitative Criminology. 22(4): 299-317.

Gorton, Gary B. and Rouwenhorst, K. Geert. 2005. Facts and Fantasies about Commodity Futures. Yale ICF Working Paper No. 04-20

Graham, B. and Jason Zweig. 2003. The Intelligent Investor: HarperCollins.

Hansen, LP, and TJ Sargent. 2001. Acknowledging misspecification in macroeconomic theory. Review of Economic Dynamics 4 (3):519-535.

Harvey, C.R., and Erb, C. B. 2006. The strategic and tactical value of commodity futures. Financial Analysts Journal 62 (2):69-97.

Haugen, RA, and NL Baker. 1996. Commonality in the determinants of expected stock returns. Journal of Financial Economics 41 (3):401-439. 
Hausch, DB, Y. Lo, and W. Ziemba. 1994. Efficiency of Racetrack Betting Markets: Academic Press.

Heaton, J, and D Lucas. 2000. Portfolio choice and asset prices: the importance of entrepreneurial risk. The Journal of Finance 55 (3):1163-1198.

Hodrick, Robert. 1987. The Empirical Evidence on the Efficiency of Forward and Futures Foreign Exchange Markets. Harwood Academic.

Kozhemiakin, A. 1997. The risk premium of corporate bonds. Journal of Portfolio Management (Winter 2006).

Malkiel, BG. 1995. Returns from investing in equity mutual funds 1971 to 1991. Journal Of Finance 50:549-549.

Moskowitz, T. J., and A. Vissing-Jorgensen. 2002. The returns to entrepreneurial investment: A private equity premium puzzle? American Economic Review 92 (4):745-778.

Nelson, DB. 1991. Conditional heteroskedasticity in asset returns: a new approach. Econometrica 59 (2):347-370.

Ni, Sophie X. 2007. Stock Option Returns: A Puzzle: SSRN.

Penman, Sh, Sa Richardson, And I Tuna. 2007. The book-to-price effect in stock returns: accounting for leverage. Journal of Accounting Research 45 (2):427-467.

Pesendorfer, W. 1995. Design innovation and fashion cycles. American Economic Review 85:771-792.

Rayo, L, and GS Becker. 2007. Evolutionary efficiency and happiness. Journal of Political Economy 115 (2):302-337.

Rubinstein, Mark. 2006. A History of the Theory of Investments. Wiley.

Ritter, Jay, and Welch, Ivo. 2002. Review of IPO Activity, Pricing, and Allocations. Journal of Finance. 57 (4).

Sharpe, W. F. 1965. Risk-Aversion In The Stock-Market - Some Empirical-Evidence. Journal of Finance 20 (3):416-422.

Treynor, J, and K Mazuy. 1966. Can mutual funds outguess the market. Harvard Business Review 44 (4):131-136.

Wermers, R. 2000. Mutual fund performance: an empirical decomposition into stock-picking talent, style, transactions costs, and expenses. The Journal of Finance 55 (4):1655-1703.

Whitelaw, RF. 1994. Time variations and covariations in the expectation and volatility of stock market returns. Journal Of Finance 49:515-515.

Ziemba, W., and Donald B. Hausch. 1984. Beat the Racetrack. Harcourt. 